
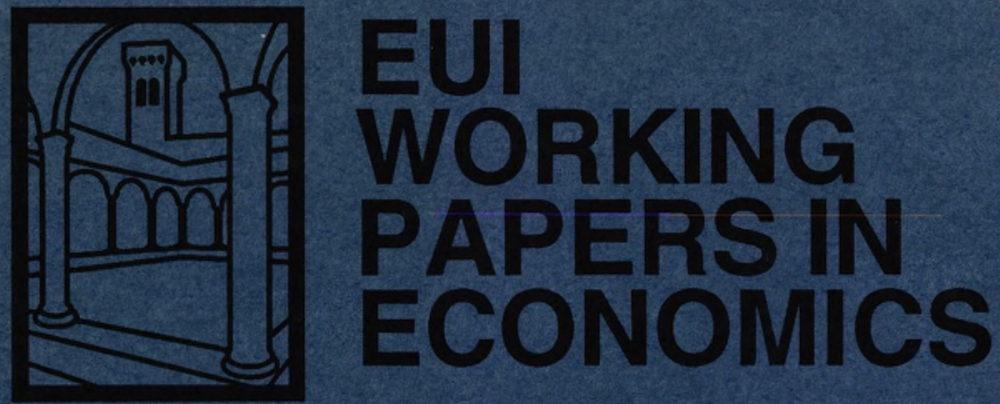

EUI Working Paper ECO No. 93/15

Short-Term Analysis of Macroeconomic Time Series

AGUSTÍN MARAVALL 
European University Library

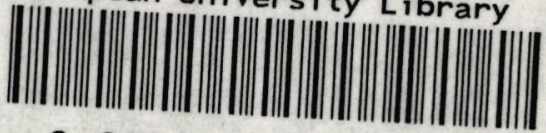

30001001496530

\section{Please note}

As from January 1990 the EUI Working Paper Series is divided into six sub-series, each sub-series is numbered individually (e.g. EUI Working Paper LA W No. 90/1). 
EUROPEAN UNIVERSITY INSTITUTE, FLORENCE ECONOMICS DEPARTMENT

EUI Working Paper ECO No. 93/15

Short-Term Analysis of Macroeconomic Time Series AGUSTÍN MARAVALL 
All rights reserved.

No part of this paper may be reproduced in any form without permission of the author.

(C) Agustín Maravall

Printed in Italy in March 1993

European University Institute

Badia Fiesolana

I - 50016 San Domenico (FI)

Italy 


\title{
Short-Term Analysis of Macroeconomic Time Series
}

\author{
Agustín Maravall*
}

December 1992

\begin{abstract}
The paper deals with statistical treatment of macroeconomic data for short-run economic analysis, monitoring and control. The main applications are short-term forecasting and unobserved components estimation, including trend and cycle estimation, and, most often, seasonal adjustment. The paper briefly reviews some of the recent developments in the field, both at the methodological and applied levels. Then, it is argued that a fairly general approach, based on signal extraction methods and ARIMA models, will gradually spread as the dominant methodology. The last section contains a word of caution, and illustrates the danger of applying these short-term statistical tools to long-term economic analysis.
\end{abstract}

*European University Institute, Badia Fiesolana, I-50016 Florence, Italy,

Tel.: +39-55-5092.347, Fax: +39-55-5092.202 


\section{Introduction}

I shall be talking about statistical treatment of short-term macroeconomic data. In particular, I shall focuss on monthly time series of standard macroeconomic aggregates, such as monetary aggregates, consumer price indices, industrial production indices, export and import series, employment series, to quote a few examples. The statistical treatment considered is that aimed at helping economic policy makers in short-term control, and at facilitating monitoring and interpretation of the economy by analysists in general. The purpose of the statistical treatment is to answer two basic questions, well summarized by P.G. Wodehouse when answering a question concerning his physical shape (Wodehouse, 1981, p. 577): "The day before yesterday, for instance, (the weighing machine in my bathroom) informed me - and I don't mind telling you, J.P., that it gave me something of a shock - that I weighed seventeen stone nine. I went without lunch and dined on a small biscuit and a stick of celery, and next day I was down to eleven stone one. This was most satisfactory and I was very pleased about it, but this morning I was up again to nineteen stone six, so I really don't know where I am or what the future holds." The two separate - though related - questions are:

(a) where are we?

(b) where are we heading?

Of course, forecasting provides the answer to (b). The answer to question (a) usually consists of an estimation of the present situation, free of seasonal variation; on occasion, variation judged transitory is also removed. Thus seasonal adjustment and trend estimation are used to answer question (a). For monthly macroeconomic series, it is often the case that seasonal variation dominates the short-run variability of the series.

In the next sections I will briefly review the recent evolution of the statistical methodology used in this context, and will provide a (justified) forecast of how I would expect it to evolve over the next ten years. The discussion will address the evolution in terms of research and in terms of practical applications (such as, for example, official seasonal adjustment). While the former typically contains a lot of noise, practical applications lag research by several (sometimes many) years.

Whenever confronted with forecasting an event, one is bound to look first at the present and past history. I shall do that, and from the (critical) look, my forecast will emerge in a straightforward and unexciting manner. The discussion centers on tools used for short-term analysis; at the end we present an example that illustrates the unreliability of these tools when our horizon is a long-term one.

\section{Short-Term Forecasting}

I shall start with a very brief mention to short-term forecasting in economics. Leaving aside judgemental (or "expert") forecasting, in the remote past, some determin- 
istic models, such as for example models with linear trends and seasonal dummies were used for short-term forecasting. This practice gave way to the use of "ad hoc" filters, which became popular in the fifties and sixties; examples are the exponentially weighted moving average method (Winters, 1960), and the discounted least squares method of Brown (1962). In the decade of the seventies, the work of Box and Jenkins (1970) provoked a revolution in the field of applied forecasting; this revolution was further enhanced by another factor: the discovery by economic forecasters of the Kalman Filter (see, for example, Harrison and Stevens, 1976). The Box-Jenkins approach offered a powerful, easy to learn and easy to apply, methodology for short-term forecasting; the Kalman filter provided a rather convenient tool to apply and extend the methodology.

The outcome was a massive spread of statistical models (simple parametric stochastic processes) and, in particular, of the so-called Autoregressive Integrated Moving Average (ARIMA) model, and of its several extensions, such as Intervention Analysis and Transfer Function models (see Box and Tiao, 1975, and Box and Jenkins, 1970), and of the closely related Structural Time Series models (see Harvey, 1989). One can safely say that ARIMA models are used everyday by thousands of practitioners. Some use is also made of multivariate versions of these models (for example, see Litterman, 1986), although multivariate extensions have often been frustrating.

The point we wish to make for now is that, overall, stochastic model-based forecasting has become a standard procedure. At present, two important directions of research are:

(1) Multivariate extensions, where the relatively recent research on cointegration and common factors may lead to an important break (through a reduction in dimensionality and an improved model specification).

(2) Nonlinear extensions, such as the use of bilinear, ARCH, GARCH, stochastic parameter models, and so on.

I would expect direction (1) to eventually play a very important role in applied short-term forecasting over the next decade. As for the future impact of direction (2), I doubt that in the next years stochastic nonlinear models will become a standard tool for the average practitioner.

\section{Unobserved Components Estimation and Sea- sonal Adjustment}

Back to question (a) of section 1, we proceed to the problem of estimating the relevant underlying evolution of an economic variable, that is, to seasonal adjustment and trend estimation issues. Two good references that describe the present state of the art concerning seasonal adjustment are Den Butter and Fase (1991) and Hylleberg (1992). As with forecasting, deterministic models were used in the distant 
past. At present, however, I do not know of any official agency producing monthly seasonally adjusted macroeconomic data that removes seasonality with deterministic dummy variables. (In fact, the only major use of deterministic seasonal adjustment at present seems to be academic research!)

It is widely accepted by practitioners that, typically, seasonality in macroeconomic series is of the moving type, for which the use of filters is appropriate. If $x_{t}$ denotes the series of interest (perhaps in logs), $n_{t}$ the seasonally adjusted series, and $s_{t}$ the seasonal component, a standard procedure is to assume

$$
x_{t}=n_{t}+s_{t}
$$

and to estimate $s_{t}$ by

$$
\hat{s}_{t}=C(B) x_{t}
$$

where $B$ is the lag operator such that $B^{k} x_{t}=x_{t-k}$ ( $k$ integer), and $C(B)$ is the linear and symmetric filter

$$
C(B)=c_{0}+c_{1}(B+F)+\ldots+c_{r}\left(B^{r}+F^{r}\right),
$$

with $F=B^{-1}$. Of course, the filter $C(B)$ is designed to capture variability of the series in a (small) interval around each seasonal frequency. The seasonally adjusted series is, in turn, estimated by

$$
\hat{n}_{t}=[1-C(B)] x_{t}=A(B) x_{t},
$$

and $A(B)$ is also a centered, linear, and symmetric filter.

The symmetric and complete filters (1) and (3) cannot be used to estimate $s_{t}$ or $n_{t}$ when $t$ is close to either end of the series. Specifically, at time $T$, when the available series is $\left(x_{1}, \ldots, x_{T}\right)$, estimation of $s_{t}$ with (1) for $t<r$ requires unavailable starting values of $x$; analogously, estimation of $s_{t}$ for $t>T-r$ requires future observations not yet available. Therefore, the centered and symmetric filter characterizes "historical" estimates. For recent enough periods asymmetric filters have to be used, which yield preliminary estimators. As time passes and new observations become available, those preliminary estimators will be revised until the historical or final estimator is eventually obtained. To this issue we shall come back later.

In the same way that 1970 marks an important date for applied short-term forecasting (i.e., the year of publication of the book by Box and Jenkins), 1967 marks a crucial event in the area of seasonal adjustment. That event was the uppearance of the program X11, developed by the U.S. Bureau of the Census (see Shiskin et al., 1967). Except for some outlier treatment (which we shall ignore), X11 can be seen as a sequence of linear filters, and hence as a linear filter. For the discussion that follows, we use the parsimonious approximation to X11 (historical filter) of Burridge and Wallis (1984). Figure 1 plots the transfer function (in the frequency domain) of the X11 monthly filter $A(B)$. This transfer function represents, for each frequency, which proportion of the variablity of $x_{t}$ is used to estimate the seasonally 
adjusted series. It is seen how the X11 filter passes the variation associated with all frequencies, except for some small intervals around the seasonal ones.

Over the next decade, X11 spread at an amazing speed, and many thousands of series came to be routinely adjusted with X11. It was an efficient and easy-touse procedure that seemed to provide good results for many series (although the meaning of "good" for seasonal adjustment is somewhat unclear). Yet, towards the end of the seventies some awareness of X11 limitations started to develop. Those limitations were mostly associated with the rigidity of the X11 filter, i.e., with its "ad hoc" relatively fixed structure. To these limitations we turn next.

\section{Limitations of Ad-hoc Filtering}

We shall provide simple illustrations of some major limitations of fixed ad-hoc filters such as X11.

(1) The danger of spurious adjustment is illustrated in figure 2. In a white-noise series, with spectrum that of part $a$ in the figure, X11 will extract a seasonal component, with spectrum that of part $b$. This spectrum is certaintly that of a seasonal component, but the series had no seasonality to start with.

(2) In the previous white-noise series, trivially, the filter $A(B)$ to seasonally adjust the series should simply be 1 ; on the other extreme, if the observed series has a spectrum as in part $b$ of figure 2, the filter to seasonally adjust the series should obviously be 0 , since the series only contains seasonal variation. The filter should depend, thus, on the characteristics of the series.

To illustrate the point, we use the well-known "Airline model" of Box and Jenkins (1970, chap. 9). It is a model appropriate for monthly series displaying trend and seasonality. For series in logs, the model implies that the annual difference of the monthly rate of growth is a stationary process. The Airline model is, on the one hand, a model often encountered in practice; on the other hand, it provides an excellent reference example. The model is given by the equation

$$
\nabla \nabla_{12} x_{t}=\left(1-\theta_{1} B\right)\left(1-\theta_{12} B^{12}\right) a_{t}+\mu,
$$

where $\mu$ is a constant, $a_{t}$ is a white-noise innovation (with variance $V_{a}$ ), $\nabla=$ $1-B, \quad \nabla_{12}=1-B^{12}, \quad$ and $-1<\theta_{1}<1, \quad 0<\theta_{12}<1$. The series $x_{t}$, generated by (4), accepts a rather sensible decomposition into trend, seasonal, and irregular component (see Hillmer and Tiao, 1982). As $\theta_{1}$ approaches 1, model (4) tends towards the model

$$
\nabla_{12} x_{t}=\left(1-\theta_{12} B^{12}\right) a_{t}+\mu_{0}+\mu t
$$

with deterministic trend. Similarly, when $\theta_{12}$ becomes 1 , the seasonal component becomes deterministic. Thus, the parameter $\theta_{1}\left(\theta_{12}\right)$ may be interpreted as a measure of how close to deterministic the trend (seasonal) component is. 
In the frequency domain this "closer to deterministic" behavior of a component is associated with the width of the spectral peaks. Thus, for example, figure 3 displays the spectra of two series both following models of the type (4). The one with the continuous line contains more stochastic seasonal variation, in accordance with the wider spectral peaks for the seasonal frequencies. The seasonal component in the series with spectrum given by the dotted line will be more stable, and hence closer to deterministic. Since the X11 seasonal adjustment filter displays holes of fixed width for the seasonal frequencies, it follows that X11 will underadjust when the width of the seasonal peak in the series spectrum is larger than that captured by the X11 filter. Figure 4a illustrates this situation, and Figure $4 \mathrm{~b}$ displays the spectrum of the estimated seasonally adjusted series obtained in this case. The underadjustment is reflected in the two peaks that remain in the neighborhood of each seasonal frequency: obviously X11 has not removed all seasonal variation from the series. (An example of this type of underadjustment is found when using X11 on the Spanish series of the Industrial Production Index).

On the other hand, X11 will overadjust (i.e., will remove too much variation from the series) when the width of the seasonal spectral peaks are narrower than those captured by X11. This effect is evidenced in figure 5: the holes in the seasonally adjusted series spectrum (part $b$ of the figure) are now too wide. (An example of this type of overadjustment is found when applying X11 to the Spanish Consumer Price Index).

(3) Another limitation of X11 is the lack of a proper framework for detecting the cases in which its application is inappropriate. On the one hand, diagnostics are few and difficult to interpret. Moreover, when found inappropriate, there is no systematic procedure to overcome the inadequacies.

(4) Even when appropriate, X11 does not contain the basis for proper inference. For example, what are the standard errors associated with the estimated seasonal factors? This limitation has important policy implications (see Bach et al., 1976, and Moore et al., 1981). In short-term monetary control, if the monthly target for the rate of growth of $M_{1}$ (seasonally adjusted) is $10 \%$ and actual growth for that month turns out to be $13 \%$, can we conclude that growth has been excessive and raise, as a consequence, short-term interest rates? Can the 3 percent points (p.p.) difference be attributed to the error implied by the estimation of the seasonally adjusted series? Similarly, when assessing the evolution of unemployment, if the series of total employment grows by 90.000 persons in a quarter, and the seasonal effect for that quarter is estimated as an increase of 50.000 persons, can we assume that the increase has been more than a pure seasonal effect?

(5) In the same way that X11 does not provide answers to these questions, it does not allow us to compute optimal forecasts of the components. (Seasonal factors for the year ahead are simply computed by adding to this year factors one half of the difference between them and the factors one year before. Of 
course, there is no measure of the uncertainty associated with these forecasts.)

(6) Although X11 computes separate estimates of the trend, seasonal, and irregular components, their statistical properties are not known. Therefore, it is not possible to answer questions such as, for example, whether the trend or the seasonally adjusted series provide a more adequate signal of the relevant underlying evolution of the series (see Kenny and Durbin, 1982, Moore et al., 1981, and Maravall and Pierce, 1986).

To overcome some of those limitations, throughout the years X11 has been subject to modifications. In particular, the program X11 ARIMA, developed by Statistics Canada (see Dagum, 1980), improved upon X11 in several ways. First, it incorporated several new elements for diagnosis. Perhaps more relevantly, it provided better estimators of the components at the end of the series. This was achieved by replacing the ad-hoc X11 filters for the preliminary estimators with a procedure in which the series is extended with ARIMA forecasts, so that the filter $A(B)$ can be applied to the extended series (and hence to more recent periods). In fact, X11 ARIMA has replaced X11 in many standard applications.

At present, the U.S. Bureau of the Census is experimenting with a new program for seasonal adjustment: X12 ARIMA (see Findley et al., 1992). The program follows the direction of X11 ARIMA, and incorporates some new sets of diagnostics and some new model-based features, having to do with the treatment of outliers and with estimation of special effects.

Be that as it may, practical applications (such as "official" seasonal adjustment by agencies) lag with respect to research. So, let us turn to the evolution of research during the last 10 or 15 years.

\section{The Model-Based Approach}

Towards the end of the seventies and beginning of the eighties a new approach to the problem of estimating unobserved components in time series, and in particular to seasonal adjustment, was developed. The approach combined two elements: one, the use of simple parametric time series models (mostly, of the ARIMA type); second, the use of signal extraction techniques. Although there were earlier attempts at using signal extraction on time series models (see Nerlove, Grether, and Carvalho, 1979), these attempts were of limited interest because they were restricted to stationary series, while economic series are typically nonstationary.

The model-based approach has followed two general directions. One is the socalled ARIMA-Model-Based methodology, and some relevant references are Burman (1980), Hillmer and Tiao (1982), Bell and Hillmer (1984), and Maravall and Pierce (1987). The second direction follows the so-called Structural Time Series methodology, and some important references are Engle (1978), Harvey and Todd (1983), and Gersch and Kitagawa (1983). We shall refer to them as the AMB approach and the 
STS approach, respectively. Both are closely related, and share the following basic structure:

The observed series $\left[x_{t}\right]=\left[x_{1}, \ldots, x_{T}\right]$ can be expressed as the sum of several orthogonal components,

$$
x_{t}=\sum_{i} x_{i t}
$$

where each component $x_{i t}$ may be expressed as an ARIMA process (with Gaussian innovations). Thus, for example, the model for the trend, $p_{t}$, may be of the type

$$
\nabla^{2} p_{t}=\theta_{p}(B) a_{p t}
$$

where $\theta_{p}(B)$ is a polynomial in $B$, and the model for the seasonal component, $s_{t}$, is often of the form (for monthly series):

$$
\left(1+B+\ldots+B^{11}\right) s_{t}=\theta_{s}(B) a_{s t},
$$

specifying that the sum of 12 consecutive seasonal components is a zero-mean stationary process (with "small" variance). While the trend and seasonal components are typically nonstationary, the irregular component is a zero-mean stationary process, often simply white-noise. Since the sum of ArIma models yields an ARIMA model, the observed series $x_{t}$ also follows an ARIMA model, say

$$
\phi(B) x_{t}=\theta(B) a_{t}
$$

where $\phi(B)$ contains the stationary and nonstationary autoregressive roots.

Once the models are specified, the unobserved components are estimated as the Minimum Mean Squared Error (MMSE) estimator

$$
\hat{x}_{i t}=E\left(x_{i t} \mid\left[x_{t}\right]\right) \text {, }
$$

and this conditional expectation is computed with signal extraction techniques. (This technique is a fairly general procedure that can be applied to a variety of statistical problems besides unobserved components estimation. In particular, forecasting can be seen as the particular case when $\hat{x}_{i t}$ is the estimator of a future observation; another well-known application is interpolation of missing values.) The MMSE estimator (6) obtained in the model-based approach is also a linear filter, symmetric, centered, and convergent in both directions of the past and of the future. Thus, as was the case with filter (2), the filter applies to historical estimates, and the problem of preliminary estimation and revisions again reappears. The modelbased approach offers an optimal solution: the observed series are extended with forecasts (and backcasts) as needed, and the symmetric and centered filter can then be applied to the extended series. (In terms of the observed values, the filter will be, of course, asymmetric; see Cleveland and Tiao, 1976.)

The decomposition of $x_{t}$ into unobserved components presents a basic identification problem. In general, the AMB and STS methods use somewhat different 
assumptions in order to reach identification; these different assumptions, of course, lead to differences in the specification of the component models. It is the case, however, that the STS trend and seasonal components can be expressed as the ones obtained from an AMB approach with superimposed orthogonal white noise (see Maravall, 1985). Ultimately, the crucial assumption for identification of the components concerns the amount of variance assigned to the irregular; the AMB approach, in order to maximize the stability of the trend and seasonal components, maximizes the irregular component variance.

Besides these differences in the specification of the component models, there are some additional ones between the two approaches. The AMB method starts by specifying the model for the observed series, following standard Box-Jenkins techniques. From this aggregate model, the component models are then derived, and the conditional expectation (6) is obtained with the Wiener-Kolmogorov filter (see Whittle, 1963, and Bell, 1984). On the contrary, the STS method starts by directly specifying the models for the components, and uses the Kalman filter to compute the conditional expectation (6); see Harvey (1989).

Despite the differences, the two approaches are quite similar and I will not address the issue of which one is preferable. My (probably biased) view is that the AMB method, by using the data to identify the model, is less prone to misspecification. I find it reasonable, moreover, in the absence of additional information, to provide trend and seasonal components as smooth as possible, within the limits of the overall stochastic behavior of the observed series. Further, the AмB method typically implies direct estimation of fewer parameters, and provides results that are more robust and numerically stable. On the other hand, the state space-Kalman filter format in the STS methodology offers the advantage of its programming and computational simplicity and flexibility. In any case, both methods provide interesting and relatively powerful tools for unobserved components estimation in linear stochastic processes. It is worth noticing that many ad-hoc procedures can be given a minimum MsE-model-based interpretation for particular ARIMA models (see, for example, Cleveland and Tiao, 1976, Burridge and Wallis, 1984, and Maravall, 1993).

\section{The Virtues of a Model-Based Method}

The major advantage of a model-based method is that it provides a convenient framework for straightforward statistical analysis. To illustrate the point we shall return to the 6 examples used when illustrating the limitations of ad-hoc filtering in section 4. As the model-based method, we use the AMB one and, in particular, a program called SEATS ("Signal Extraction in ARIMA Time Series"); see Maravall and Gómez (1992). The program SEATS originally developed from a program built by Burman for seasonal adjustment at the Bank of England. (At present, SEATS is a fairly complete unobserved components estimation - and forecasting - program within an AMB approach; it is available, together with documentation, upon 
request.)

(1) The danger of spurious adjustment is certainly attenuated: if a series is whitenoise, it would be detected at the identification stage, and no seasonal adjustment would be performed.

(2) The dangers of underadjustment (figure 4) and overadjustment (figure 5) are also greatly reduced. The parameters of the ARIMA model will adapt themselves to the width of the spectral peaks present in the series. Figure 6 illustrates the seasonal adjustment (with the AMB method) of the series in figure 4: part (a) illustrates how the filter adapts itself to the seasonal spectral peaks, and part (b) shows how the spectrum of the estimated seasonally adjusted series shows no evidence now of underadjustment. AMB seasonal adjustment of the series with a very stable seasonal (the series of figure 5) is displayed in figure 7. The filter now captures a very narrow band, and the spectrum of the adjusted series estimator does not provide evidence of overadjustment.

(3) To illustrate how the model-based approach can provide elements of diagnostics, we use an example from Maravall (1987). The example also illustrates how, when the diagnostic is negative, one can proceed in order to improve upon the results.

When adjusting with X11 the Spanish monthly series of insurance operations (a small component of the money supply), the program indicated that there was too much autocorrelation in the irregular estimator, $\hat{u}_{t}$. In fact, the lag-1 autocorrelation of $\hat{u}_{t}$ was .42 .

For a model-based method with a white-noise irregular component, $u_{t}$, the MMSE estimator $\hat{u}_{t}$ has the Autocorrelation Funcion (ACF) of the "inverse" model of (5), that is of the model obtained by interchanging the AR and the MA polynomials. Hence, given the model for the observed series, the theoretical value of the ACF for $\hat{u}_{t}$ is easily obtained. For the model-based interpretation of X11 (for which $u_{t}$ is white-noise), one finds $\rho_{1}\left(\hat{u}_{t}\right)=-.2$ with a standard error of .1. Thus a $95 \%$ confidence interval for $\rho_{1}$ would be, approximately, $(-.40,0)$. Since the value obtained, .42 , is far from the interval, it is clear that there is indeed too much autocorrelation in the irregular.

The relative large, positive, autocorrelation in $\hat{u}_{t}$ seems to indicate underestimation of the trend. The ARIMA model for which X11 provides an MMSE filter contains the stationary transformation $\nabla \nabla_{12}$. Having had a negative diagnostic, back to the identification stage, it was found that a model with the transformation $\nabla^{2} \nabla_{12}$, which allowed for a more stochastic trend, provided a better fit of the series. For this model, the value of $\rho_{1}\left(\hat{u}_{t}\right)$ was -.83 , with $\mathrm{SE}=.05$. АмB decomposition of the series with the new model specification yielded an irregular with $\rho_{1}=-.82$, perfectly in agreement with what should have been obtained. 
Thus the model-based approach offers a natural set-up for carrying out diagnostics, and permits to improve upon the results by applying the standard iterations (identification/estimation/diagnosis, and back to identification) of a model-building procedure.

(4) As for the possibility of drawing inference, I mentioned the importance of measuring the errors associated with the estimated components.

Given the model, the estimator (6) contains two types of errors. First, when $t$ is not far from the two ends of the series, a preliminary estimator will be obtained. Consider the case of concurrent estimation, that is the estimation of $x_{i t}$ when the last observation is $x_{t}$. As new observations become available, eventually the preliminary estimator will become the final one (i.e., the one that yields historical estimators). The difference between the preliminary and final estimator is the "revision error". The second type of error is the one contained in the final estimator, implied by the stochastic nature of the component. The revision error and the error in the final estimator are orthogonal (Pierce, 1980).

With the model-based approach, it is straightforward to compute variances and autocorrelations of each type of error (see Maravall and Gómez, 1992). Thus, in the examples used in point (4) of section 4, the AMB method of SEATS yields the following answers: The standard error in the estimator of the monthly rate of growth of the seasonally adjusted Spanish monetary aggregate series is 1.95 percent points. Thus, with a $95 \%$ size we cannot reject the hypothesis that the measurement of $13 \%$ growth is in agreement with the $10 \%$ target. (If the size is reduced to $70 \%$, then the measured growth becomes significantly different from the target.)

As for the quarterly series of Spanish employment, the standard error of the seasonal component estimator is equal to 19.000 persons. Thus the 90.000 increase could be (barely) accepted as significantly more than the seasonal effect of 50.000 .

(5) The model-based approach provides MMSE forecasts of the components, as well as their associated standard errors. For example, for the Spanish monthly series of imports, the standard errors of the 1 and 12 periods-ahead forecasts for the original series, the seasonally adjusted series, and the trend, are the following (in \% of the level):

$\begin{array}{rccc} & \text { Series } & \text { SA Series } & \text { Trend } \\ 1 \text { p.a. forecast } & 11.6 & 11.0 & 5.4 \\ 12 \text { p.a. forecast } & 14.9 & 14.6 & 11.0\end{array}$

The trend, thus, appears to be a considerably more precise forecasting tool.

The standard errors of the components provide answers to many problems of applied interest. For example, it is clear that optimal updating of preliminary seasonally adjusted data implies re-estimation whenever a new observation 
becomes available. This "concurrent" adjustment implies a very large amount of work; in particular, it requires agencies producing data to change every month many series for many years. So, the overwhelming practice is to adjust once a year, and it is of interest to know how much precision is lost by this suboptimal procedure. This can be easily computed and, for the import series, moving from a once-a-year seasonal adjustment to a concurrent one decreases the root mean squared error (on average) by $10 \%$. Given real life limitations, it would seem to me a case in which the improvement hardly justifies the effort.

(6) In the previous point we compared the forecast errors of the trend and seasonally adjusted series. Since the two can be taken as alternative signals of the relevant underlying evolution of the series, it is of interest to look at a more complete comparison of their relative performances. Consider now the Spanish monthly series of exports. An Airline-type model fits well the series, although the series has a large forecast error variance. In terms of the components, this is associated with a large irregular component.

Starting with concurrent estimation (the case of most applied interest), the variances of the different types of errors, expressed as fractions of the variance of $a_{t}$ (the residuals of the ARIMA model), are the following:

$\begin{array}{ccc} & \text { SA Series } & \text { Trend } \\ \text { Revision Error } & .073 & .084 \\ \text { Final Estimation Error } & .085 & .068 \\ \text { TOTAL ERROR } & .158 & .152\end{array}$

Therefore, the error contained in the concurrent estimator of the two signals is roughly equal. The error in the final estimator is smaller for the trend; in turn, the seasonally adjusted series is subject to smaller revisions.

But, besides the size of the full revision in the concurrent estimator, it is of interest to know how fast the estimator converges to the final value. After one year of additional data, for the trend component, $92 \%$ of the revision standard deviation has been completed. The percentage drops to $28.8 \%$ for the seasonally adjusted series. Thus the trend estimator converges much faster to its final value.

Often, policy makers or analysts are more interested in looking : t rates of growth than in looking at levels. Three of the most popular ones are the monthly rate of growth of the monthly series, $r_{1}$, the monthly rate of growth of a 3-month moving average, $r_{3}$, and the annual rate of growth centered in the present month, $r_{12}$ (that is, the growth over the last 6 months plus the forecasted growth over the next 6 months). Both $r_{1}$ and $r_{3}$ are annualized and the three rates are expressed in percent points. The standard errors of the concurrent estimators of the 3 rates of growth are found to be: 


$\begin{array}{lccc} & \text { Series } & \text { SA Series } & \text { Trend } \\ r_{1} & - & 85.3 & 21.4 \\ r_{3} & - & 47.4 & 16.1 \\ r_{12} & 14.3 & 13.9 & 8.8\end{array}$

Thus, an attempt to follow the evolution of exports by looking at the monthly rate of growth of the seasonally adjusted series would be likely to induce a manic-depressive behavior in policy makers and analysts (similar to the one reported by Wodehouse).

Finally, the standard error of the 1-period-ahead forecast of the series is $12.6 \%$ of the level of the series. For the seasonally adjusted series, the corresponding forecast error becomes $11 \%$, and it drops to $4.5 \%$ for the trend component.

From the previous results it is clear that for the case of the export series (and a similar comment applies to the series of imports) the seasonally adjusted series provides a highly volatile and unstable signal, and the use of the trend in month-to-month monitoring seems certainly preferable.

\section{The Next Ten Years}

In the previous section I have tried to illustrate some of the advantages of a modelbased approach in short-term analysis of macroeconomic data. In fact, the modelbased approach can be a powerful tool, and it is gradually becoming available to the community of applied statisticians and economists. The speed of its diffusion, however, is damped by two basic problems. The first one is the inertia that characterizes burocratic institutions producing large amounts of economic data (old habits die hard!). The second is that, when dealing with many series, individual identification of the correct model for each series is, in practice, unfeasible.

This second limitation is, in my opinion, more apparent than real. The Airline model provides a good default option, and can provide a reasonable approximation to many series. (It is a three-parameter model, with one parameter reflecting the stability of the trend, a second parameter reflecting the stability of the seasonal component, and a third parameter reflecting the overall predictability of the series.) When the model is not adequate, the alternatives are reasonably limited. Stationarity-inducing transformations different from $\nabla \nabla_{12}$ can be $\nabla_{12}$ or $\nabla^{2} \nabla_{12}$, and it is very unlikely that higher degrees of differencing need to be used. As for the stationary part, no more than 3 or 4 parameters are likely to be needed, and there are already some identification procedures that can be enforced in a rather efficient manner (see, for example, Tsay and Tiao, 1984, and Beguin, Gourieroux and Monfort, 1980).

My forecast for the next ten years will come, thus, as no surprise: model-baised signal extraction with ARIMA-type models will increase its importance for practical 
applications, and eventually replace X11 as the dominant methodology (although this may take more than a decade).

As for directions of new research, the extension of signal extraction to multivariate models seems to me a promising direction. I would expect to see multivariate models that incorporate the possibility that several series may share several components. This would permit a more efficient estimation of the components, and a more parsimonious multivariate model. Some preliminary steps in that direction can be found in Fernandez-Macho, Harvey and Stock (1987) and Stock and Watson (1988).

Similarly to the case of forecasting, another obvious research direction is the extension of unobserved component models to nonlinear time series. It is the case, for example, that nonlinearity often affects seasonal frequencies (see Maravall, 1983), and hence should be included when estimating seasonally adjusted series. Early efforts in this direction are Kitagawa (1987) and Harvey, Ruiz and Sentana (1992). As with forecasting, it is my belief that, over the next decade, the multivariate extension will play a more important role in applied work than the nonlinear extensions.

To complete my statements about the future, I should add a last one, well known to anybody that has been involved in actual forecasting: no matter what I might say, my forecast will most certainly be wrong.

\section{Final Comment: Limitations of the Model- Based Approach}

From the previous discussion it would seem as if the use of a model-based approach is a panacea that will permit us to obtain proper answers to all questions. Yet this panacea is not a well-defined one: what do we really mean by a model? Ultimately the models we use are not properties of an objective reality that we manage to approximate, but figments of the researcher mind. In particular, the proper model to use can only be defined in terms of the problems one wishes to analyze. In this context, ARIMA models were devised for short-term analysis, yet they have been borrowed to deal with many other applications. We shall concentrate on one, namely the efforts by macroeconomists to measure the Business Cycle and analyze the behavior of aggregate output. One of the directions of this research has been the attempt to measure the long-term effects of shocks to GNP and, in particular, to answer the question: does a unit innovation in GNP have a permanent effect on the level of GNP? This long-term effect of a unit innovation has been denoted "persistence". If $x_{t}=\log$ GNP follows the I(1) model

$$
\nabla x_{t}=\psi(B) a_{t}
$$

then the measure of persistence, $m$, can be defined as the effect of a unit innovation on the long-term forecast of $x_{t}$, or 


$$
m=\lim _{k \rightarrow \infty}\left(E_{t} x_{t+k}+E_{t-1} x_{t+k}\right)=\lim _{k \rightarrow \infty} \sum_{j=0}^{k} \psi_{j}=\psi(1),
$$

since $a_{t}=1$. Different values of $m$ have been indeed attributed to competing theories on the Business Cycle. Specifically, if $m>1$, real factors, associated mostly with supply, would account for the Business Cycle; on the contrary, $m<1$ would indicate that transitory, demand-type shocks play an important role in the generation of cycles.

The standard procedure to estimate $m$ has been to specify a model, then to fit it by a Maximum Likelihood (ML) or some Least Squares (LS) criteria, and then to use the parameter estimates for inference. We consider the quarterly series of US GNP (the series was kindly provided to us by George Evans, and it is the same as in Evans, 1989; it consists of 144 observations). For our purposes, a reasonable model is given by

$$
\nabla x_{t}=(1-\theta B) a_{t}+\mu
$$

where $\mu$ is a constant. ML estimation yields $\hat{\theta}=-.30$, and the residuals obtained seem to behave as white-noise. The measure of persistence becomes thus

$$
\hat{m}=1.30 \quad(\mathrm{SE}=.08),
$$

and hence it can be concluded that $m>1$. This is in agreement with many univariate estimates of $m$ found in the literature; see, for example, Campbell and Mankiw (1987).

Broadly, an ML or an Ls criterion minimize the sum of squares (Ss) of the residuals $a_{t}$ or, approximately, the Ss of the 1-period-ahead (1-p.a.) forecast error. Why select the 1-p.a. forecast? If our interest is the long-run, and this is certainly the case when measuring persistence, why not minimize a long-term forecast error? It is in fact well known that minimizing the Ss of the 1-p.a. forecast error may yield parameter estimates that differ substantially from those that minimize the Ss of the $k$-p.a. forecast (for $k$ not close to 1). Some references are Cox (1963), Gersh and Kitagawa (1983), Findley (1984), Weiss (1991), and Tiao and Xu (1992).

For our example, let $\hat{\theta}(k)$ denote the estimator that minimizes the Ss of the (in sample) $k$-p.a. forecast errors. Figure 8 displays $\hat{\theta}(k)$ as a function of $k$. For $k<20$ periods, the estimator fluctuates between -.2 and -.4 ; then it jumps fast to .94 , and for $k \geq 20$ it remains basically unchanged around that value. Curiously enough thus, the sample information seems to discriminate two values for $\theta$ : one for the short run (less than a five-year horizon) and one for the long run (more than a five-year horizon). A closer look at the behavior of the Ss function - Figure 9 - shows that, for low values of $k$, a clear minimum is found for a small, negative value of $\theta$. Then, for the intermediate values $k=10-20$, the Ss function becomes very flat. As $k$ becomes larger, the minimum for $\theta=.95$ becomes more and more pronounced. (A similar result is obtained by Tiao and $\mathrm{Xu}, 1992$.) If we compute the $\%$ increase in the MSE of the forecast from using the ML estimator instead of $\hat{\theta}(k)$, it is found that, for $k<20$, that percentage is negligible (in line with the results in 
Weiss, 1991, who considers values of $k \leq 4$.) For $k=24$, use of the ML estimator $\hat{\theta}(1)$ increases the MSE by $14 \%$; for $k=32$, this percentage becomes $26 \%$, and for $k=40$, it goes up to $31 \%$. Therefore, if our aim is the long-term forecast, it would seem quite inefficient to use as parameter $\hat{\theta}(1)=-.30$ : our MSE may deteriorate by more than $30 \%$.

It is easy to find an explanation for the behavior of $\hat{\theta}(k)$. The good performance of ARIMA models is a result of their flexibility to adapt their forecast function to the short-run variability. Long-run extrapolation of this short-run flexibility will introduce too much noise in the long-term forecast.

Again, a look at the model components will prove helpful. The $\operatorname{IMA}(1,1)$ model of (8) can be seen as the sum of a trend and an orthogonal white-noise component, where the variance of the noise component can take any value in the interval $\left(0,(1+\theta)^{2} V_{a} / 4\right)$; see Box, Hillmer and Tiao (1978). In the trend plus noise decomposition of (8), the forecast of the series is the same as the forecast of the trend. The two models obtained by setting $\theta=-.3$ and $\theta=.95$ will imply very different trend components. To compare them, we select the decomposition of (8) that sets the variance of the noise equal to its maximum in the above interval; this is the so-called canonical decomposition, and it maximizes the smoothness of the trend. For the two canonical decompositions corresponding to $\theta=-.3$ and $\theta=.95$, the variances of the innovations in the trend component are $.423 V_{a}$ and $.001 V_{a}$, respectively. When $\theta=.95$, the trend contains, thus, very little stochastic variability. The two spectra are compared in figure 10. This comparison shows that the trend implied by the model that is optimal for long-term forecasting is very stable, and picks up only very small frequencies. This is a sensible result: when interested in short-term analysis, we look at the month-to-month or quarter-toquarter forecasts. Thus, for example, the variability of the series associated in the spectrum with the frequency corresponding to a period of 5 years should be a part of the forecast and of the trend. However, if we are forecasting 20 years ahead, the (finite) variance of the series corresponding to a 5-year cycle should not be considered, and hence should not be a part of the trend: in 20 years, the (damped) 5 -year cycle has practically disappeared. This is precisely what figure 10 tells us. When looking at the long run, only movements in the series associated with very large periods, i.e., very small frequencies, are of interest. Figure 11 compares the two (short-term and long-term) trend estimates and the two associated estimates of the noise component. The short-run noise reflects the estimator of a white-noise variable; the long-run noise instead allows for larger effects, since over a long span of time they approximately cancel out.

If the measure of persistence, which attempts to measure the effect of a shock on the very long-term forecast, is based on the model optimal for long-term forecasting, then

$$
\hat{m}=1-.95=.05 \text {. }
$$

quite differently from the one obtained before, and certainly below one. Yet the 
point is not to claim that this result points towards a business cycle dominated by demand shocks. The way I read it, the conclusion is that the trend model obtained in the standard ML estimation-ARIMA specification approach only makes sense for relatively short-term analysis. It is with this type of analysis that I have been concerned in this paper, and it seems to me that the short-term tools we use may not be appropriate for long-term inference. 


\section{References}

Bach, G.L., Cagan, P.D., Friedman, M., Hildreth, C.G., Modigliani, F. and OKun, A. (1976), Improving the Monetary Aggregates: Report of the Advisory Committee on Monetary Statistics, Washington, D.C.: Board of Governors of the Federal Reserve System.

Beguin, J.M., Gourieroux, C. and Monfort, A. (1980), "Identification of a Mixed Autoregressive-Moving Average Process: The Corner Method", in O.D. Anderson (ed.) Time Series (Proceedings of a March 1979 Conference), Amsterdam: North-Holland.

Bell, W.R. (1984), "Signal Extraction for Nonstationary Time Series", The Annals of Statistics 12, 2, 646-664.

Bell, W.R. and Hillmer, S.C. (1984), "Issues Involved with the Seasonal Adjustment of Economic Time Series", Journal of Business and Economic Statistics $2,4,291-320$.

Box, G.E.P., Hillmer, S.C. and TiaO, G.C. (1978), "Analysis and Modeling of Seasonal Time Series", in A. ZelLner (ed.), Seasonal Analysis of Economic Time Series, Washington, D.C.: U.S. Dept. of Commerce - Bureau of the Census, 309-334.

Box, G.E.P. and Jenkins, G.M. (1970), Time Series Analysis: Forecasting and Control, San Francisco: Holden-Day.

Box, G.E.P. and TIAO, G.C. (1975), "Intervention Analysis with Applications to Economic and Environmental Problems", Journal of the American Statistical Association 70, 71-79.

Brown, R.G. (1962), Smoothing, Forecasting and Prediction of Discrete Time Series, New Jersey: Prentice-Hall.

Burman, J.P. (1980), "Seasonal Adjustment by Signal Extraction", Journal of the Royal Statistical Society A, 143, 321-337.

Burridge, P. and Wallis, K.F. (1984), "Unobserved Components Models for Seasonal Adjustment Filters", Journal of Business and Economic Statistics 2, 350-359.

Campbell, J.Y. and Mankiw, N.G. (1987), "Permanent and Transitory Components in Macro-economic Fluctuations", American Economic Review Proceedings 1987, 111-117.

Cleveland, W.P. and Tiao, G.C. (1976), "Decomposition of Seasonal Time Series: A Model for the X-11 Program", Journal of the American Statistical Association $71,581-587$.

Cox, D.R. (1961), "Prediction by Exponentially Weighted Moving Averages and Related Methods", Journal of the Royal Statistical Society B, 23, 414-422. 
Dagum, E.B. (1980), "The X11 Arima Seasonal Adjustment Method", Statistics Canada, Catalogue 12-564E.

Den Butter, F.A.G. and Fase, M.M.G. (1991), Seasonal Adjustment as a Practical Problem, Amsterdam: North-Holland.

Engle, R.F. (1978), "Estimating Structural Models of Seasonality", in A. Zellner (ed.), Seasonal Analysis of Economic Time Series, Washington, D.C.: U.S. Dept. of Commerce - Bureau of the Census, 281-297.

Evans, G.W. (1989), "Output and Unemployment Dynamics in the United States: 1950-1985", Journal of Applied Econometrics 4, 213-237.

Fernandez-Macho, F., Harvey, A.C. and Stock, J.H. (1987), "Forecasting and Interpolation Using Vector Autoregressions with Common Trends", Annales d'Economie et de Statistique 6/7, 279-288.

Findley, D.F. (1984), "On Some Ambiguities Associated with the Fitting of Arma Models to Time Series", Journal of Time Series Analysis 5, 217-227.

Findley, D.F., Monsell, B., Otto, M., Bell, W. and Pugh, M. (1992), "Towards X-12 ARIMA", mimeo, Bureau of the Census.

Gersch, W. and Kitagawa, G. (1983), "The Prediction of Time Series with Trends and Seasonalities", Journal of Business and Economic Statistics 1, 253-264.

Harrison, P.J. and Stevens, C.F. (1976), "Bayesian Forecasting", Journal of the Royal Statistical Society B, 38, 205-247.

Harvey, A.C. (1989), Forecasting, Structural Time Series Models and the Kalman Filter, Cambridge: Cambridge University Press.

Harvey, A.C., Ruiz, E. and Sentana, E. (1992), "Unobserved Component Time Series Models with ARCH Disturbances", Journal of Econometrics 52, 129-157.

Harvey, A.C. and Todd, P.H.J. (1983), "Forecasting Economic Time Series with Structural and Box-Jenkins Models: A Case Study", Journal of Business and Economic Statistics 1, 4, 299-306.

Hillmer, S.C. and Tiao, G.C. (1982), "An Arima-Model Based Approach to Seasonal Adjustment", Journal of the American Statistical Association 77, 6370.

Hylleberg, S. (ed.) (1992), Modeling Seasonality, New York: Oxford University Press.

Kenny, P. and Durbin, J. (1982), "Local Trend Estimation and Seasonal Adjustment of Economic and Social Time Series", Journal of the Royal Statistical Society A, 145, 1-28.

Kitagawa, G. (1987), "Non-Gaussian State Space Modeling of Nonstationary Time Series", Journal of the American Statistical Association 82, 1032-1063. 
Litterman, R.B. (1986), "A Statistical Approach to Economic Forecasting", Journal of Business and Economic Statistics 4, 1-5.

Maravall, A. (1983), "An Application of Non-Linear Time Series Forecasting", Journal of Business and Economic Statistics 1, 1.

Maravall, A. (1985), "On Structural Time Series Models and the Characterization of Components", Journal of Business and Economic Statistics 3, 4, 350-355.

Maravall, A. (1987), "On Minimum Mean Squared Error Estimation of the Noise in Unobserved Component Models", Journal of Business and Economic Statistics 5, 115-120.

Maravall, A. (1993), "Stochastic Linear Trends: Models and Estimators", Journal of Econometrics 54, 1-33.

Maravall, A. and Gómez, V. (1992), "Signal Extraction in Arima Time Series: Program Seats", Eui Working Paper Eco No. 92/65, Department of Economics, European University Institute.

Maravall, A. and Pierce, D.A. (1986), "The Transmission of Data Noise into Policy Noise in U.S. Monetary Control", Econometrica 54, 961-979.

Maravall, A. and Pierce, D.A. (1987), "A Prototypical Seasonal Adjustment Model", Journal of Time Series Analysis 8, 177-193.

Moore, G.H., Box, G.E.P., Kaitz, H.B., Stephenson, J.A. and Zellner, A. (1981), Seasonal Adjustment of the Monetary Aggregates: Report of the Committee of Experts on Seasonal Adjustment Techniques, Washington, D.C.: Board of Governors of the Federal Reserve System.

Nerlove, M., Grether, D.M. and Carvalho, J.L. (1979), Analysis of Economic Time Series: A Synthesis, New York: Academic Press.

Pierce, D.A. (1980), "Data Revisions in Moving Average Seasonal Adjustment Procedures", Journal of Econometrics 14, 1, 95-114.

Shiskin, J., Young, A.H. and Musgrave, J.C. (1967), "The X11 Variant of the Census Method II Seasonal Adjustment Program", Washington, D.C.: Bureau of the Census, Technical Paper 15.

Stock, J.H. and Watson, M.W. (1988), "Testing for Common Trends", Journal of the American Statistical Association 83, 1097-1107.

TIAO, G.C. and XU, D. (1992), "Robustness of MLE for Multi-Step Predictions: The Exponential Smoothing Case", Technical Report 117, Statistics Research Center, Graduate School of Business, The University of Chicago.

TSAY, R.S. and TiaO, G.C. (1984), "Consistent Estimates of Autoregressive Parameters and Extended Sample Autocorrelation Function for Stationary and Non-Stationary ARma Models", Journal of the American Statistical Association 79, 84-96. 
WeISS, A.A. (1991), "Multi-step Estimation and Forecasting in Dynamic Models", Journal of Econometrics 48, 135-149.

Whittle, P. (1963), Prediction and Regulation by Linear Least-Square Methods, London: English Universities Press.

Winters, P.R. (1960), "Forecasting Sales by Exponentially Weighted Moving Averages", Management Science 6, 324-342.

Wodehouse, P.G. (1981), Wodehouse on Wodehouse, Penguin Books. 


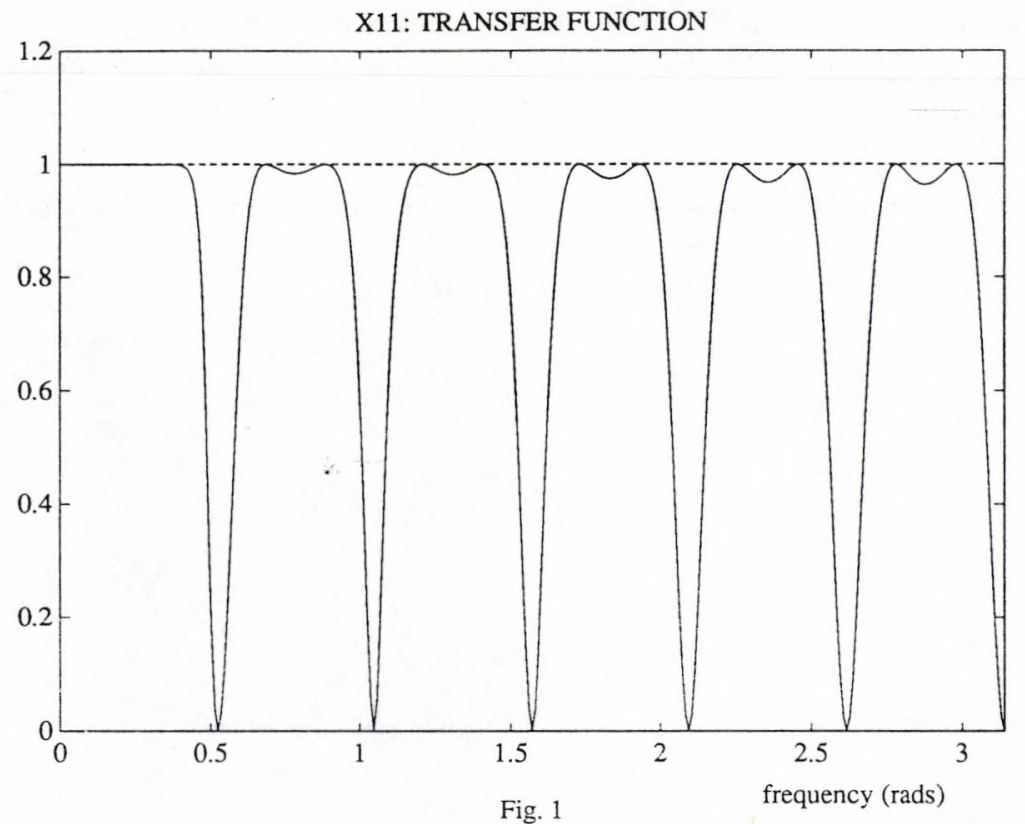

Fig. 1 
SPECTRUM: WHITE-NOISE VARIABLE

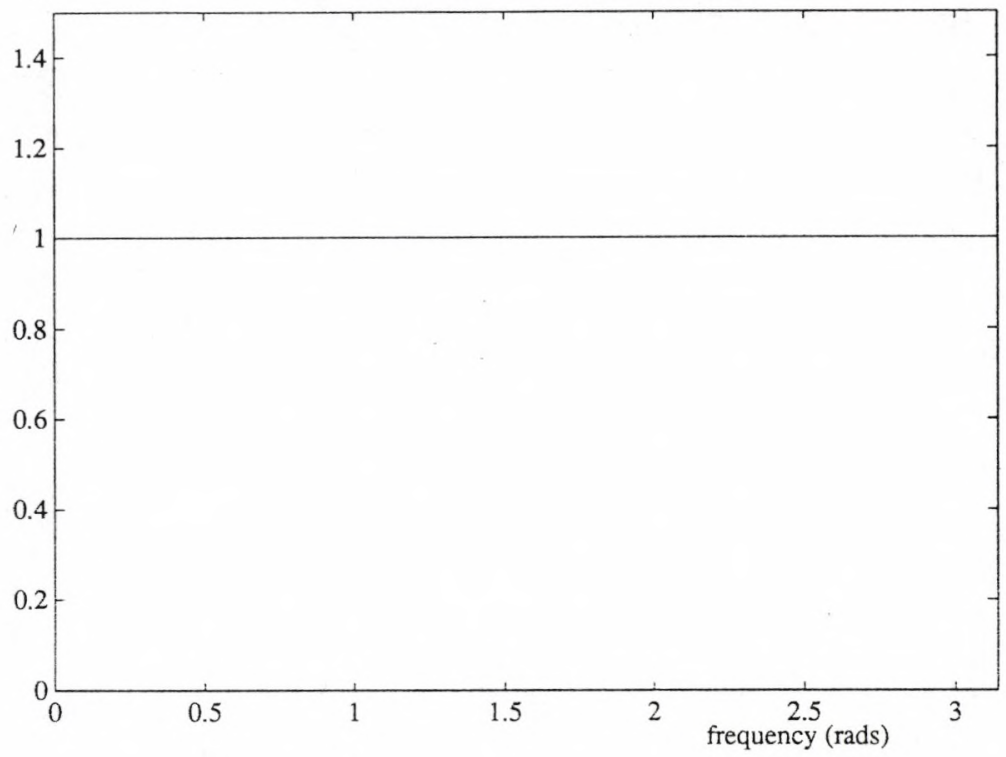

SPECTRUM: SEASONAL COMPONENT IN THE WHITE NOISE (X11)

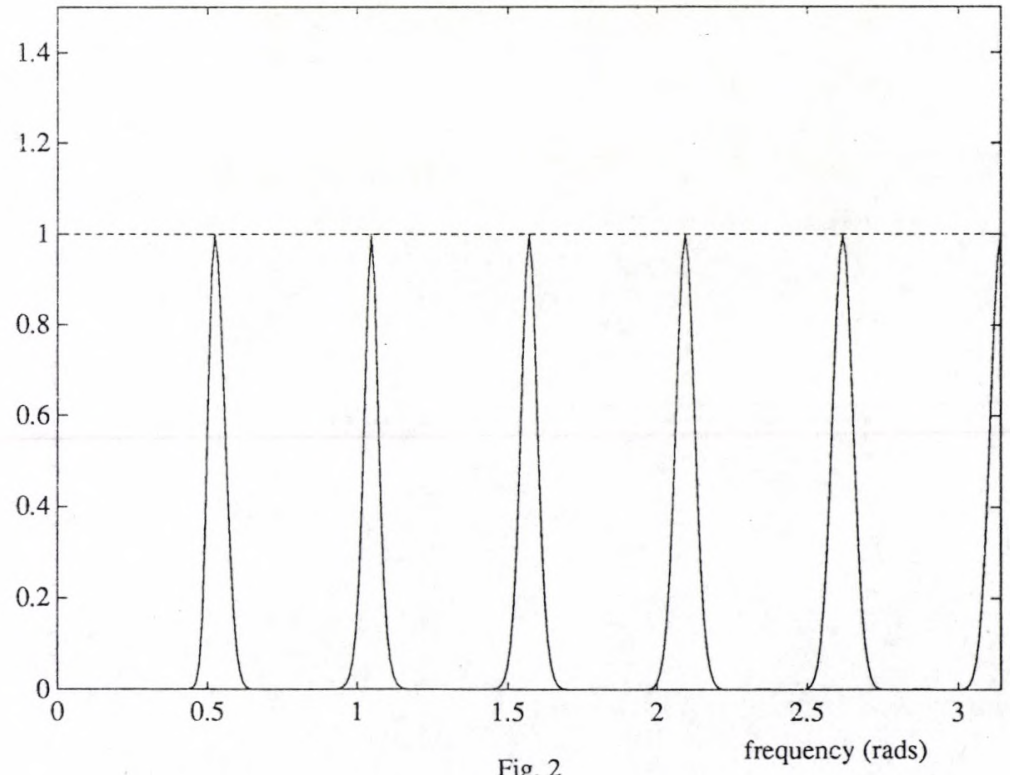

Fig. 2

frequency (rads) 


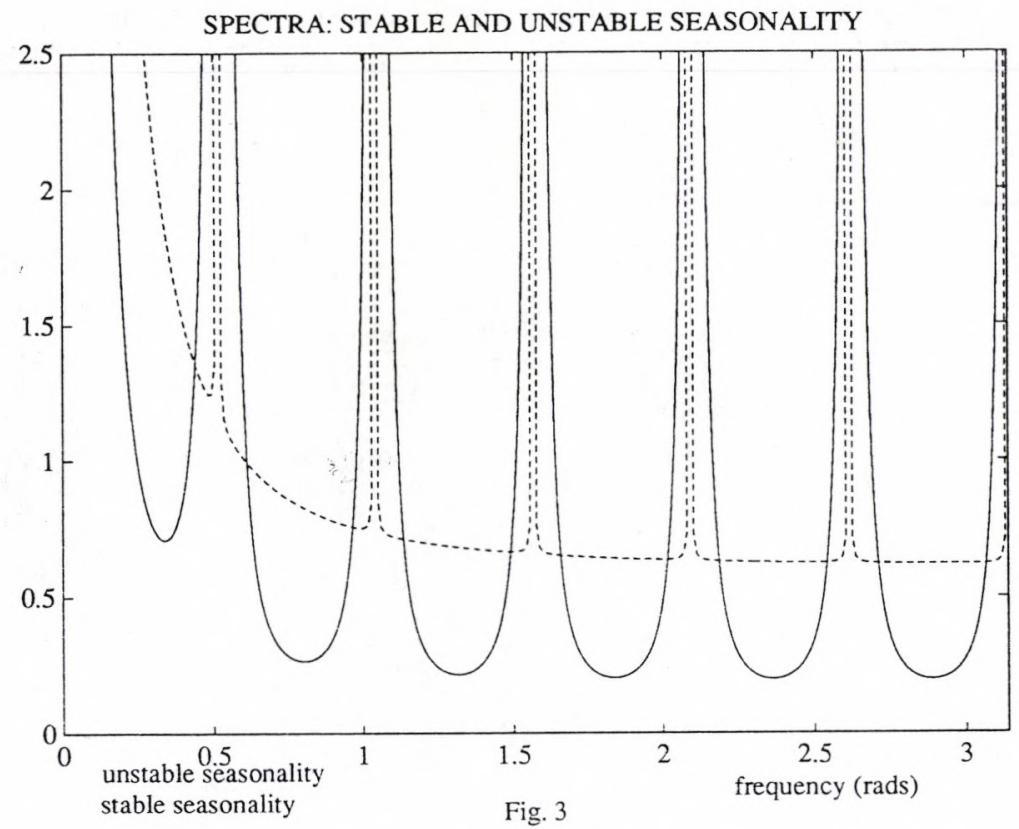

Fig. 3 

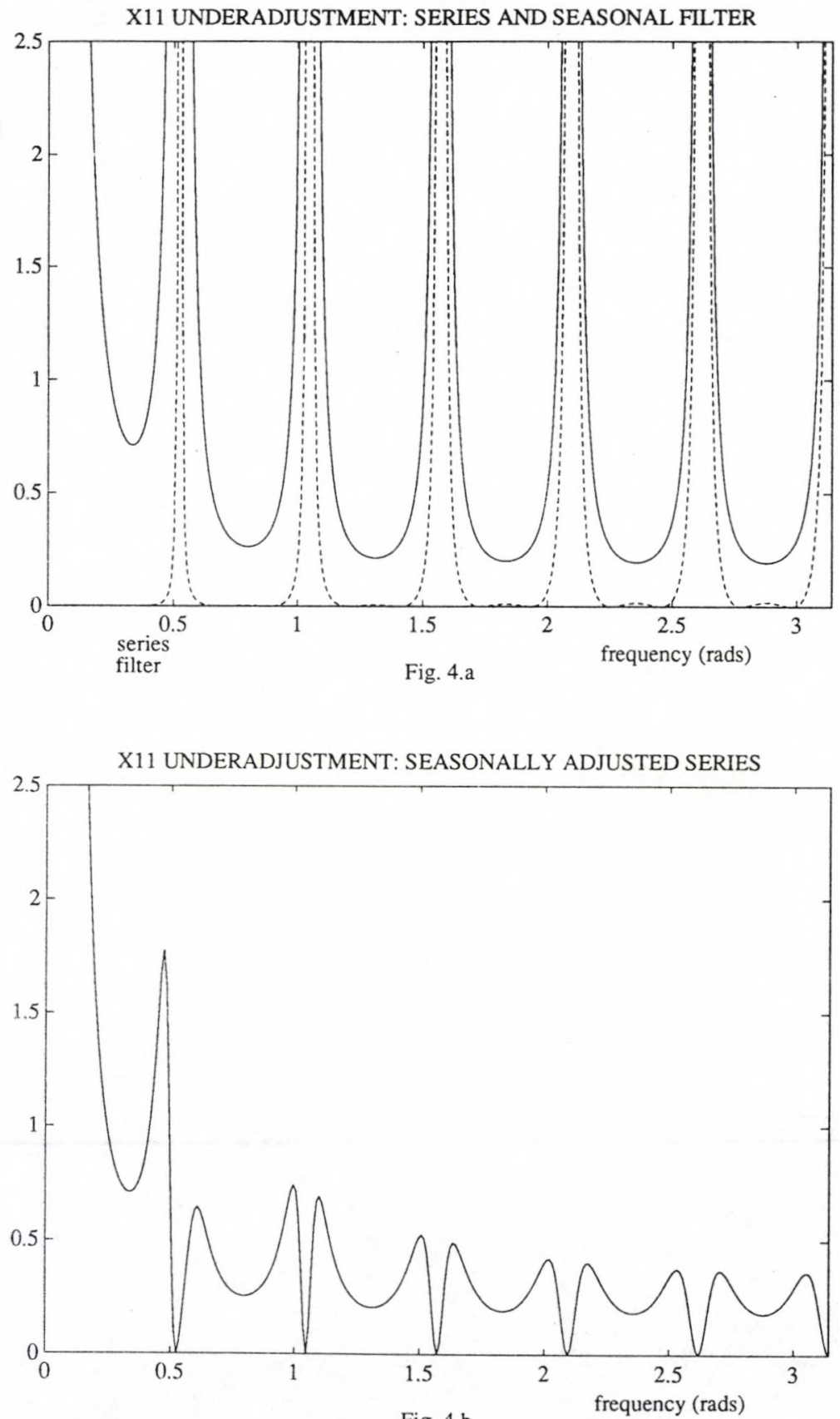

Fig. 4.b 


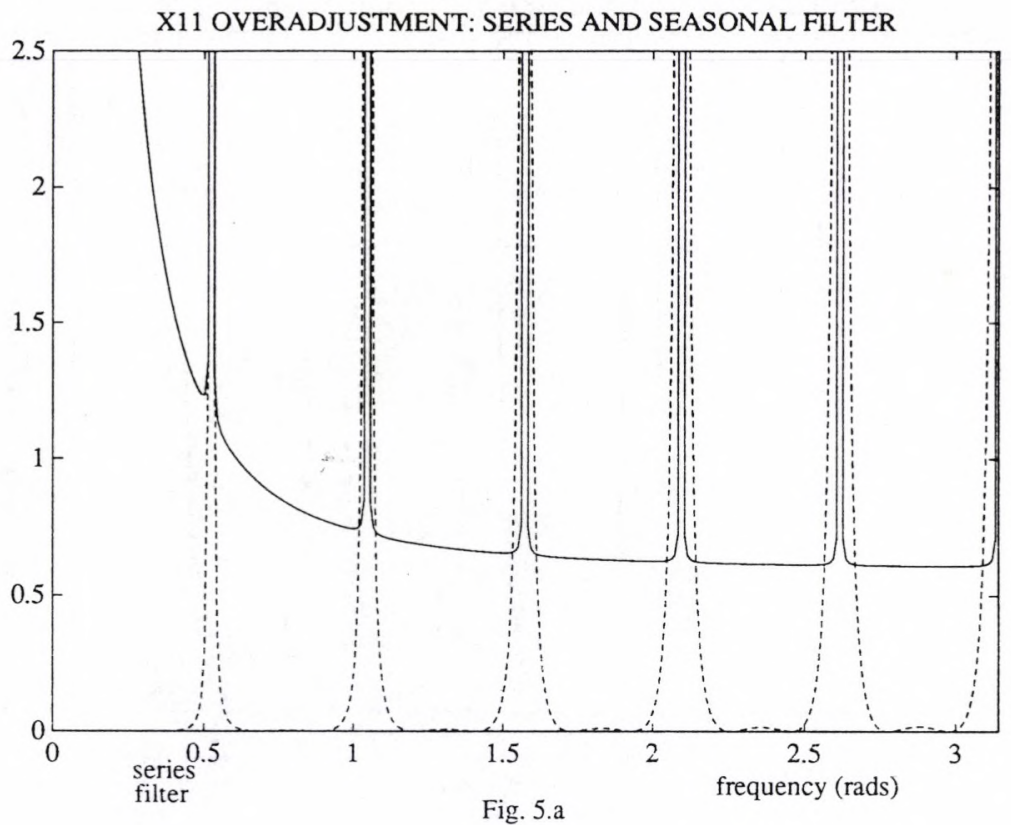

Fig. 5.a

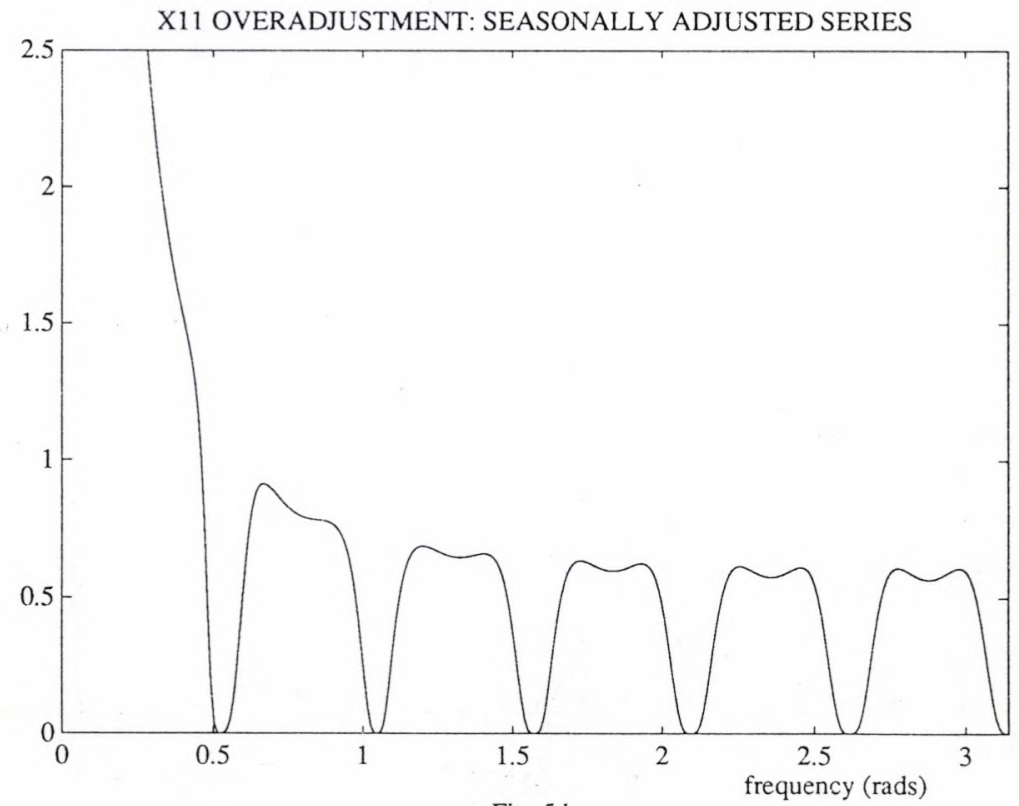

Fig. 5.b 


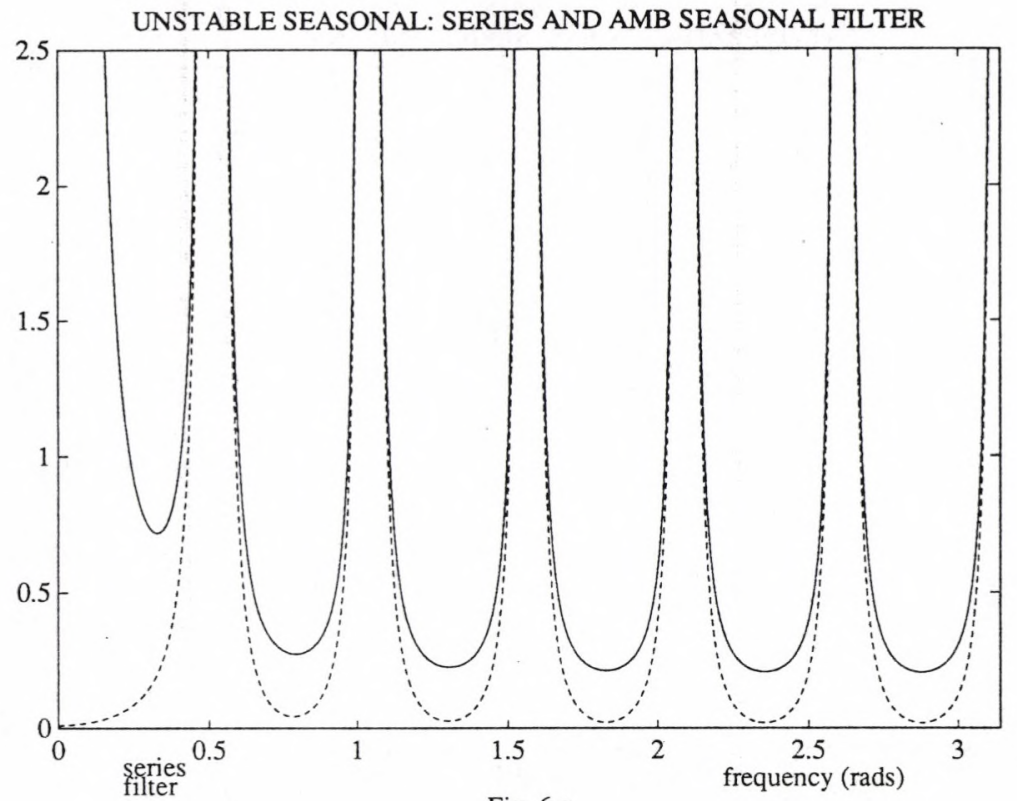

Fig. 6.a

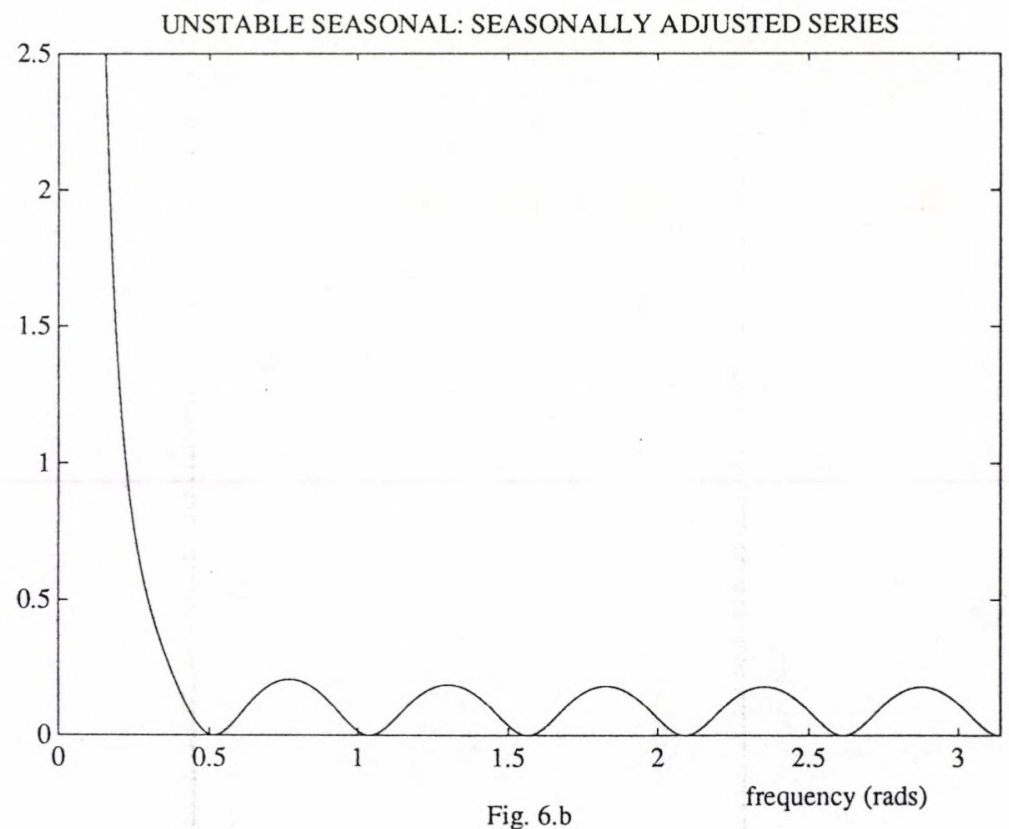




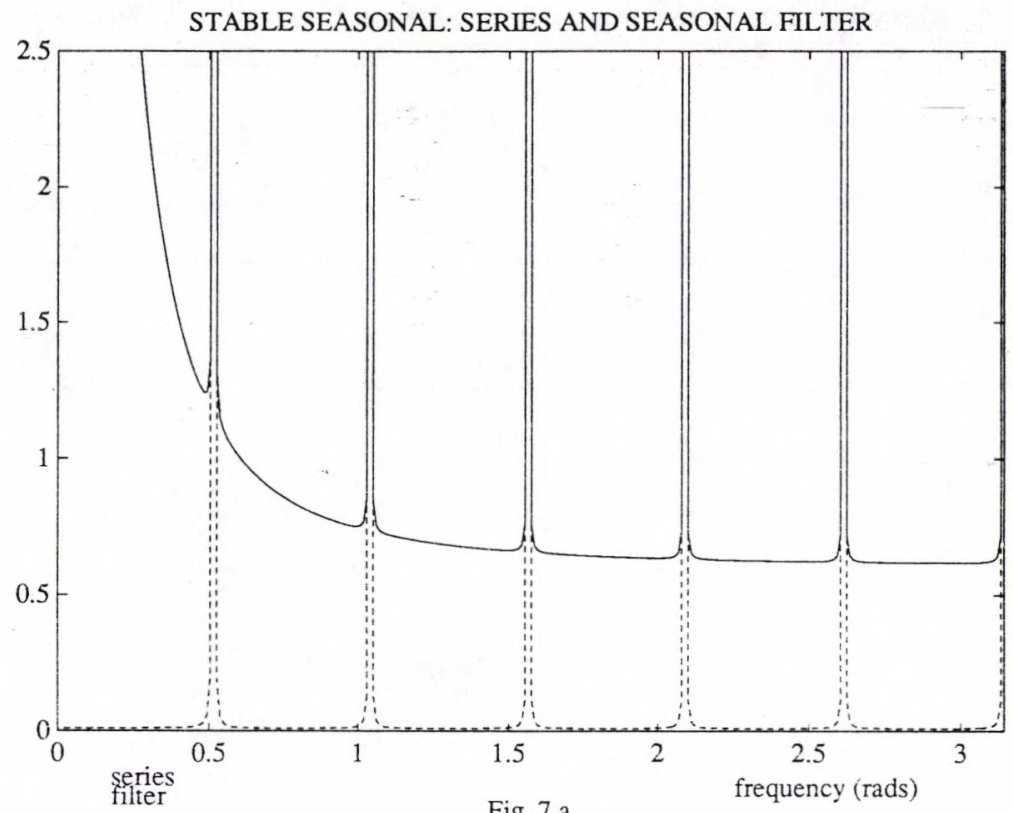

Fig. 7.a

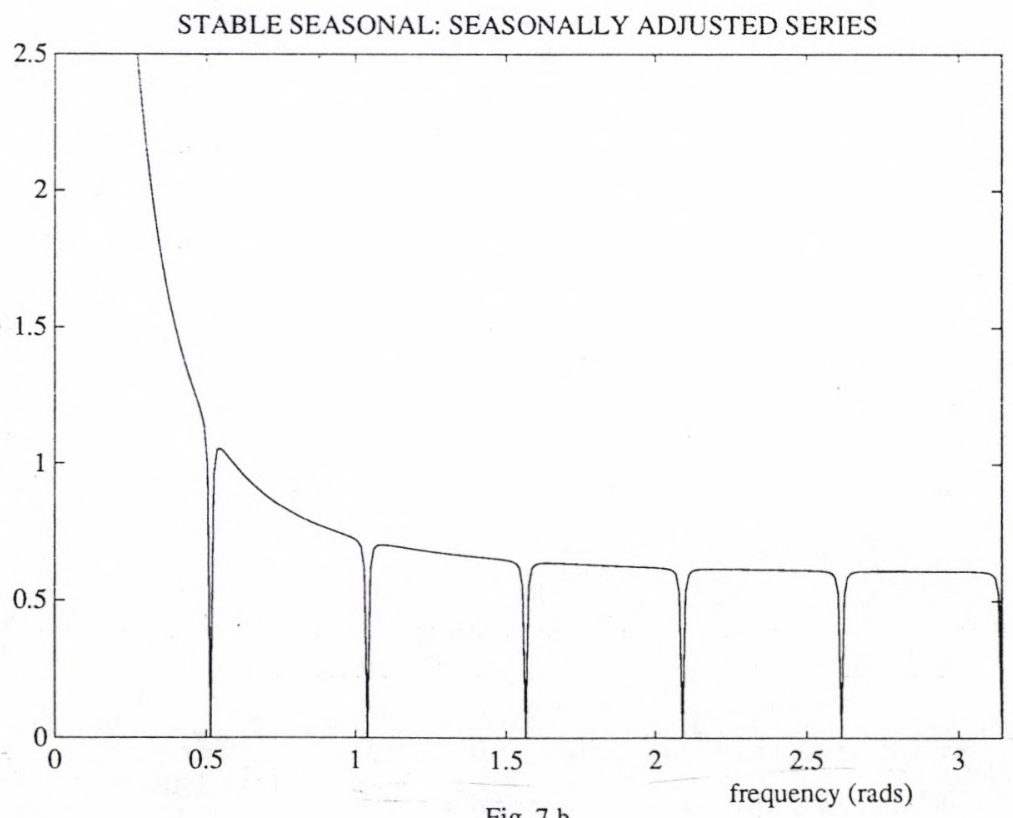

Fig. 7.b 


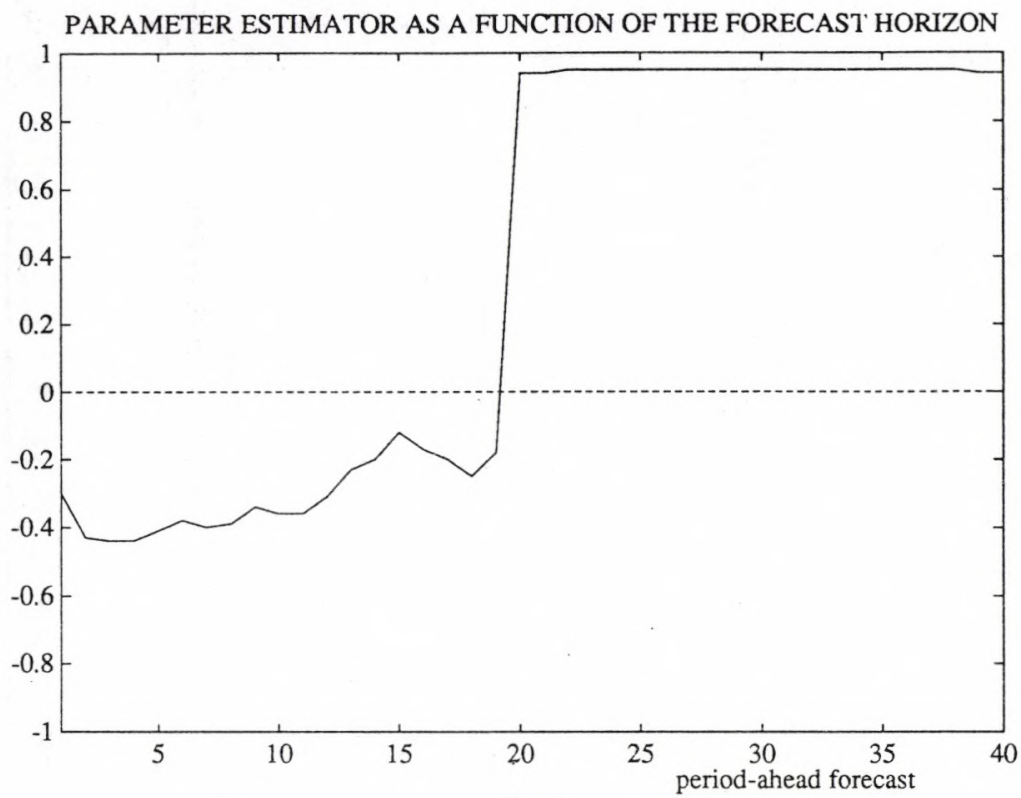

Fig. 8

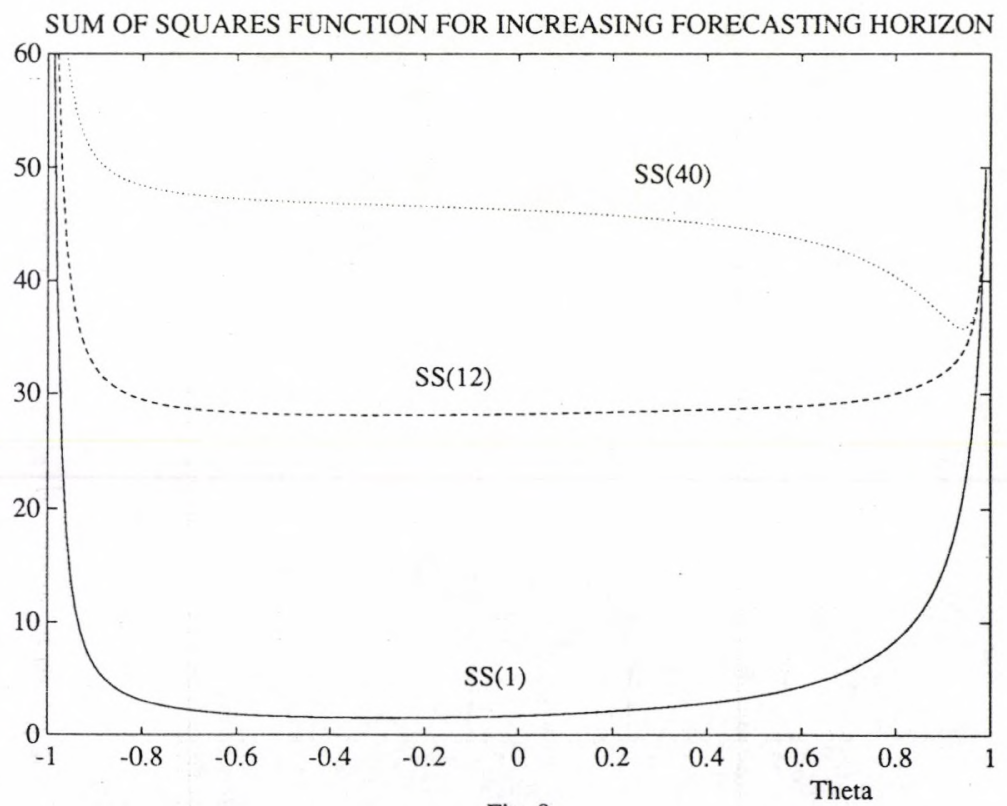

Fig. 9 
TREND SPECTRUM: SHORT AND LONG TERM MODELS

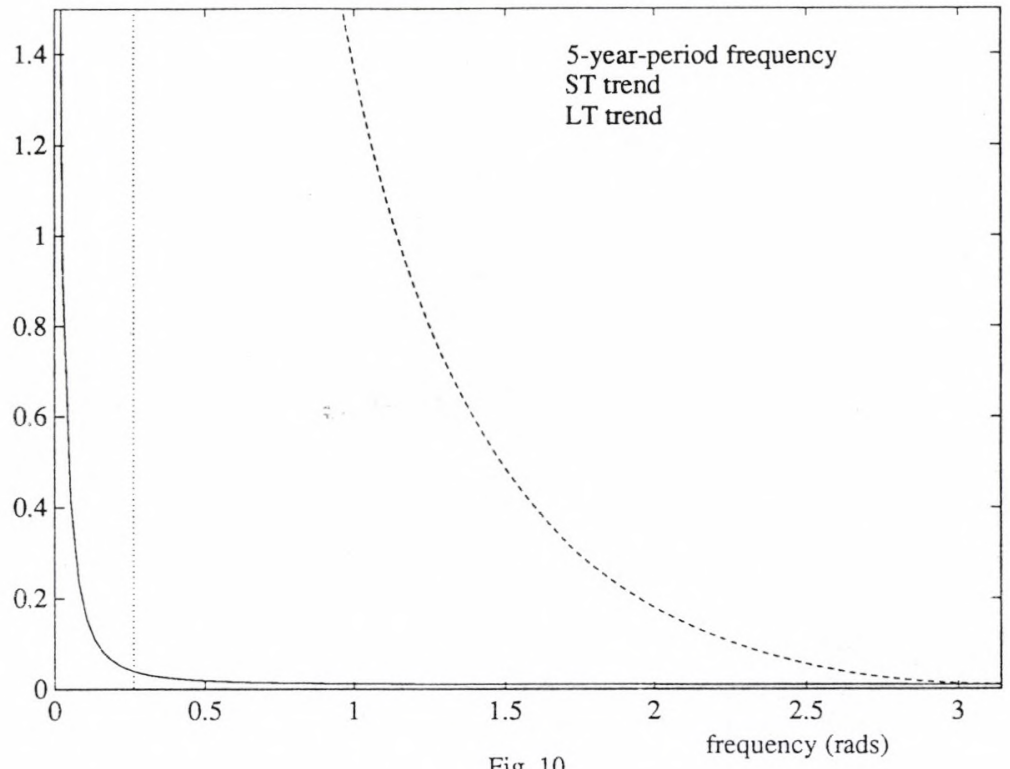

Fig. 10 

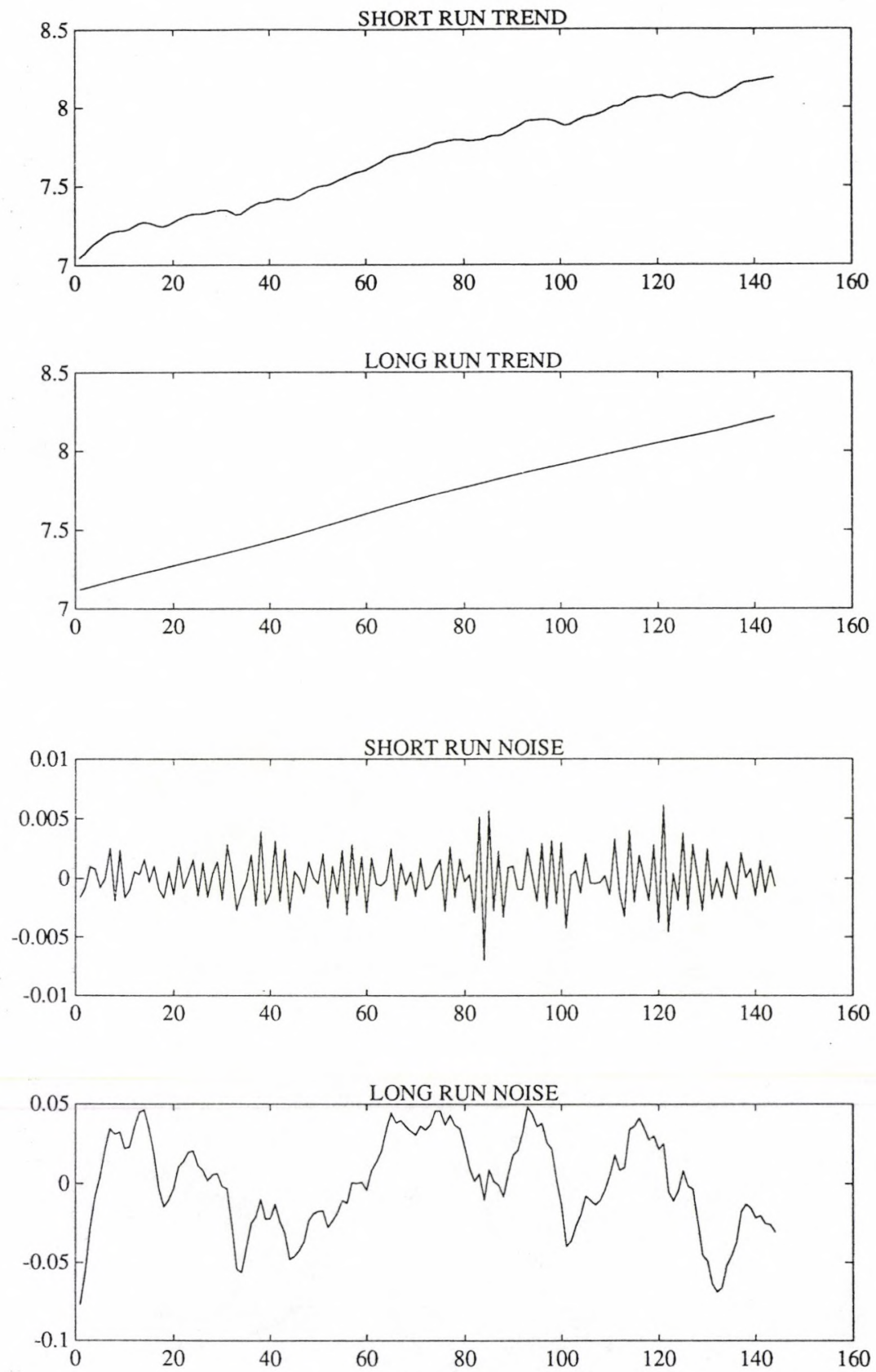

Fig. 11 


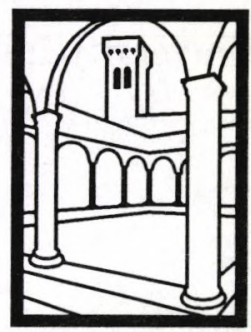

EUI Working Papers are published and distributed by the European University Institute, Florence

Copies can be obtained free of charge - depending on the availability of stocks - from:

The Publications Officer

European University Institute

Badia Fiesolana

I-50016 San Domenico di Fiesole (FI)

Italy 


\section{Publications of the European University Institute}

To The Publications Officer

European University Institute

Badia Fiesolana

I-50016 San Domenico di Fiesole (FI)

Italy

From

Name

Address.

$\square$ Please send me a complete list of EUI Working Papers

$\square$ Please send me a complete list of EUI book publications

$\square$ Please send me the EUI brochure Academic Year 1993/94

$\square$ Please send me the EUI Research Report

Please send me the following EUI Working Paper(s):

No, Author

Title:

No, Author

Title:

No, Author

Title:

No, Author

Title:

Date

Signature 


\section{Working Papers of the Department of Economics Published since 1990}

ECO No. 90/1

Tamer BASAR and Mark SALMON

Credibility and the Value of Information

Transmission in a Model of Monetary

Policy and Inflation

ECO No. 90/2

Horst UNGERER

The EMS - The First Ten Years

Policies - Developments - Evolution

ECO No. 90/3

Peter J. HAMMOND

Interpersonal Comparisons of Utility:

Why and how they are and should be made

ECO No. 90/4

Peter J. HAMMOND

A Revelation Principle for (Boundedly)

Bayesian Rationalizable Strategies

\section{ECO No. 90/5}

Peter J. HAMMOND

Independence of Irrelevant Interpersonal

Comparisons

\section{ECO No. 90/6}

Hal R. VARIAN

A Solution to the Problem of

Externalities and Public Goods when

Agents are Well-Informed

ECO No. 90/7

Hal R. VARIAN

Sequential Provision of Public Goods

ECO No. 90/8

T. BRIANZA, L. PHLIPS and J.F. RICHARD

Futures Markets, Speculation and

Monopoly Pricing

ECO No. 90/9

Anthony B. ATKINSON/ John

MICKLEWRIGHT

Unemployment Compensation and

Labour Market Transition: A Critical

Review

ECO No. 90/10

Peter J. HAMMOND

The Role of Information in Economics
ECO No. 90/11

Nicos M. CHRISTODOULAKIS

Debt Dynamics in a Small Open

Economy

ECO No. 90/12

Stephen C. SMITH

On the Economic Rationale for

Codetermination Law

ECO No. 90/13

Elettra AGLIARDI

Learning by Doing and Market Structures

ECO No. 90/14

Peter J. HAMMOND

Intertemporal Objectives

\section{ECO No. 90/15}

Andrew EVANS/Stephen MARTIN

Socially Acceptable Distortion of

Competition: EC Policy on State Aid

\section{ECO No. 90/16}

Stephen MARTIN

Fringe Size and Cartel Stability

\section{ECO No. 90/17}

John MICKLEWRIGHT

Why Do Less Than a Quarter of the Unemployed in Britain Receive

Unemployment Insurance?

ECO No. 90/18

Mrudula A. PATEL

Optimal Life Cycle Saving With

Borrowing Constraints:

A Graphical Solution

\section{ECO No. 90/19}

Peter J. HAMMOND

Money Metric Measures of Individual and Social Welfare Allowing for Environmental Externalities

ECO No. 90/20

Louis PHLIPS/

Ronald M. HARSTAD

Oligopolistic Manipulation of Spot

Markets and the Timing of Futures

Market Speculation 
ECO No. 90/21

Christian DUSTMANN

Earnings Adjustment of Temporary

Migrants

ECO No. 90/22

John MICKLEWRIGHT

The Reform of Unemployment

Compensation:

Choices for East and West

ECO No. 90/23

Joerg MAYER

U. S. Dollar and Deutschmark as

Reserve Assets

ECO No. 90/24

Sheila MARNIE

Labour Market Reform in the USSR:

Fact or Fiction?

ECO No. 90/25

Peter JENSEN/

Niels WESTERGÅRD-NIELSEN

Temporary Layoffs and the Duration of

Unemployment: An Empirical Analysis

ECO No. 90/26

Stephan L. KALB

Market-Led Approaches to European

Monetary Union in the Light of a Legal

Restrictions Theory of Money

ECO No. 90/27

Robert J. WALDMANN

Implausible Results or Implausible Data?

Anomalies in the Construction of Value

Added Data and Implications for Esti-

mates of Price-Cost Markups

ECO No. 90/28

Stephen MARTIN

Periodic Model Changes in Oligopoly

ECO No. 90/29

Nicos CHRISTODOULAKIS/

Martin WEALE

Imperfect Competition in an Open

Economy
落洸

ECO No. 91/30

Steve ALPERN/Dennis J. SNOWER Unemployment Through 'Learning From Experience'

ECO No. 91/31

David M. PRESCOTT/Thanasis

STENGOS

Testing for Forecastible Nonlinear

Dependence in Weekly Gold Rates of Return

ECO No. 91/32

Peter J. HAMMOND

Harsanyi's Utilitarian Theorem:

A Simpler Proof and Some Ethical

Connotations

ECO No. 91/33

Anthony B. ATKINSON/

John MICKLEWRIGHT

Economic Transformation in Eastern

Europe and the Distribution of Income*

ECO No. 91/34

Svend ALBAEK

On Nash and Stackelberg Equilibria when Costs are Private Information

ECO No. 91/35

Stephen MARTIN

Private and Social Incentives

to Form R \& D Joint Ventures

ECO No. 91/36

Louis PHLIPS

Manipulation of Crude Oil Futures

ECO No. 91/37

Xavier CALSAMIGLIA/Alan KIRMAN

A Unique Informationally Efficient and

Decentralized Mechanism With Fair

Outcomes

ECO No. 91/38

George S. ALOGOSKOUFIS/

Thanasis STENGOS

Testing for Nonlinear Dynamics in

Historical Unemployment Series

ECO No. 91/39

Peter J. HAMMOND

The Moral Status of Profits and Other

Rewards:

A Perspective From Modern Welfare Economics 
ECO No. 91/40

Vincent BROUSSEAU/Alan KIRMAN

The Dynamics of Learning in Mis-

Specified Models

\section{ECO No. 91/41}

Robert James WALDMANN

Assessing the Relative Sizes of Industryand Nation Specific Shocks to Output

ECO No. 91/42

Thorsten HENS/Alan KIRMAN/Louis PHLIPS

Exchange Rates and Oligopoly

\section{ECO No. 91/43}

Peter J. HAMMOND

Consequentialist Decision Theory and

Utilitarian Ethics

\section{ECO No. 91/44}

Stephen MARTIN

Endogenous Firm Efficiency in a Cournot

Principal-Agent Model

\section{ECO No. 91/45}

Svend ALBAEK

Upstream or Downstream Information Sharing?

\section{ECO No. 91/46}

Thomas H. McCURDY/

Thanasis STENGOS

A Comparison of Risk-Premium

Forecasts Implied by Parametric Versus

Nonparametric Conditional Mean

Estimators

\section{ECO No. 91/47}

Christian DUSTMANN

Temporary Migration and the Investment into Human Capital

\section{ECO No. 91/48}

Jean-Daniel GUIGOU

Should Bankruptcy Proceedings be

Initiated by a Mixed

Creditor/Shareholder?

\section{ECO No. 91/49}

Nick VRIEND

Market-Making and Decentralized Trade

\section{ECO No. 91/50}

Jeffrey L. COLES/Peter J. HAMMOND

Walrasian Equilibrium without Survival:

Existence, Efficiency, and Remedial

Policy
ECO No. 91/51

Frank CRITCHLEY/Paul MARRIOTT/

Mark SALMON

Preferred Point Geometry and Statistical Manifolds

ECO No. 91/52

Costanza TORRICELLI

The Influence of Futures on Spot Price

Volatility in a Model for a Storable

Commodity

ECO No. 91/53

Frank CRITCHLEY/Paul MARRIOTT/ Mark SALMON

Preferred Point Geometry and the Local Differential Geometry of the Kullback-

Leibler Divergence

ECO No. 91/54

Peter MØLLGAARD/

Louis PHLIPS

Oil Futures and Strategic

Stocks at Sea

\section{ECO No. $91 / 55$}

Christian DUSTMANN/

John MICKLEWRIGHT

Benefits, Incentives and Uncertainty

ECO No. 91/56

John MICKLEWRIGHT/

Gianna GIANNELLI

Why do Women Married to Unemployed Men have Low Participation Rates?

ECO No. 91/57

John MICKLEWRIGHT

Income Support for the Unemployed in Hungary

ECO No. 91/58

Fabio CANOVA

Detrending and Business Cycle Facts

ECO No. 91/59

Fabio CANOVA/

Jane MARRINAN

Reconciling the Term Structure of Interest Rates with the Consumption Based ICAP Model

ECO No. 91/60

John FINGLETON

Inventory Holdings by a Monopolist Middleman 
深深

ECO No. 92/61

Sara CONNOLLY/John

MICKLEWRIGHT/Stephen NICKELL

The Occupational Success of Young Men

Who Left School at Sixteen

ECO No. 92/62

Pier Luigi SACCO

Noise Traders Permanence in Stock

Markets: A Tâtonnement Approach.

I: Informational Dynamics for the Two-

Dimensional Case

ECO No. 92/63

Robert J. WALDMANN

Asymmetric Oligopolies

ECO No. 92/64

Robert J. WALDMANN/Stephen

C. SMITH

A Partial Solution to the Financial Risk and Perverse Response Problems of Labour-Managed Firms: Industry-

Average Performance Bonds

ECO No. 92/65

Agustín MARAVALL/Víctor GÓMEZ

Signal Extraction in ARIMA Time Series Program SEATS

ECO No. 92/66

Luigi BRIGHI

A Note on the Demand Theory of the

Weak Axioms

ECO No. 92/67

Nikolaos GEORGANTZIS

The Effect of Mergers on Potential

Competition under Economies or

Diseconomies of Joint Production

ECO No. 92/68

Robert J. WALDMANN/

J. Bradford DE LONG

Interpreting Procyclical Productivity:

Evidence from a Cross-Nation Cross-

Industry Panel

ECO No. 92/69

Christian DUSTMANN/John

MICKLEWRIGHT

Means-Tested Unemployment Benefit and Family Labour Supply: A Dynamic Analysis
ECO No. 92/70

Fabio CANOVA/Bruce E. HANSEN

Are Seasonal Patterns Constant Over

Time? A Test for Seasonal Stability

ECO No. 92/71

Alessandra PELLONI

Long-Run Consequences of Finite

Exchange Rate Bubbles

ECO No. 92/72

Jane MARRINAN

The Effects of Government Spending on Saving and Investment in an Open Economy

ECO No. 92/73

Fabio CANOVA and Jane MARRINAN Profits, Risk and Uncertainty in Foreign Exchange Markets

ECO No. 92/74

Louis PHLIPS

Basing Point Pricing, Competition and Market Integration

ECO No. $92 / 75$

Stephen MARTIN

Economic Efficiency and Concentration:

Are Mergers a Fitting Response?

ECO No. 92/76

Luisa ZANCHI

The Inter-Industry Wage Structure:

Empirical Evidence for Germany and a

Comparison With the U.S. and Sweden

ECO NO. 92/77

Agustín MARAVALL

Stochastic Linear Trends: Models and

Estimators

ECO No. 92/78

Fabio CANOVA

Three Tests for the Existence of Cycles in Time Series

\section{ECO No. 92/79}

Peter J. HAMMOND/Jaime SEMPERE Limits to the Potential Gains from Market Integration and Other Supply-Side Policies 
ECO No. 92/80

Víctor GÓMEZ and Agustín

MARAVALL

Estimation, Prediction and Interpolation

for Nonstationary Series with the

Kalman Filter

ECO No. 92/81

Víctor GÓMEZ and Agustín

MARAVALL

Time Series Regression with ARIMA

Noise and Missing Observations

Program TRAM

ECO No. 92/82

J. Bradford DE LONG/ Marco BECHT

"Excess Volatility" and the German

Stock Market, 1876-1990

ECO No. 92/83

Alan KIRMAN/Louis PHLIPS

Exchange Rate Pass-Through and Market

Structure

ECO No. 92/84

Christian DUSTMANN

Migration, Savings and Uncertainty

ECO No. 92/85

J. Bradford DE LONG

Productivity Growth and Machinery

Investment: A Long-Run Look, 18701980

ECO NO. 92/86

Robert B. BARSKY and J. Bradford DE LONG

Why Does the Stock Market Fluctuate?

ECO No. 92/87

Anthony B. ATKINSON/John

MICKLEWRIGHT

The Distribution of Income in Eastern

Europe

ECO No.92/88

Agustín MARAVALL/Alexandre

MATHIS

Encompassing Unvariate Models in

Multivariate Time Series: A Case Study

ECO No. 92/89

Peter J. HAMMOND

Aspects of Rationalizable Behaviour
ECO 92/90

Alan P. KIRMAN/Robert

J. WALDMANN

I Quit

ECO No. 92/91

Tilman EHRBECK

Rejecting Rational Expectations in Panel

Data: Some New Evidence

ECO No. 92/92

Djordje Suvakovic OLGIN

Simulating Codetermination in a

Cooperative Economy

ECO No. 92/93

Djordje Suvakovic OLGIN

On Rational Wage Maximisers

ECO No. 92/94

Christian DUSTMANN

Do We Stay or Not? Return Intentions of

Temporary Migrants

ECO No. 92/95

Djordje Suvakovic OLGIN

A Case for a Well-Defined Negative

Marxian Exploitation

ECO No. 92/96

Sarah J. JARVIS/John

MICKLEWRIGHT

The Targeting of Family Allowance in Hungary

ECO No. 92/97

Agustín MARAVALL/Daniel PEÑA

Missing Observations and Additive

Outliers in Time Series Models

ECO No. $92 / 98$

Marco BECHT

Theory and Estimation of Individual and

Social Welfare Measures: A Critical

Survey

ECO No. 92/99

Louis PHLIPS and Ireneo M:guel

MORAS

The AKZO Decision: A Case of

Predatory Pricing?

ECO No. 92/100

Stephen MARTIN

Oligopoly Limit Pricing With Firm-

Specitic Cost Uncertainty 
ECO No. 92/101

Fabio CANOVA/Eric GHYSELS

Changes in Seasonal Patterns: Are They

Cyclical?

ECO No. 92/102

Fabio CANOVA

Price Smoothing Policies: A Welfare

Analysis

\section{深深}

ECO No. 93/1

Carlo GRILLENZONI

Forecasting Unstable and Non-Stationary

Time Series

ECO No. 93/2

Carlo GRILLENZONI

Multilinear Models for Nonlinear Time

Series

ECO No. 93/3

Ronald M. HARSTAD/Louis PHLIPS

Futures Market Contracting When You

Don't Know Who the Optimists Are

ECO No. 93/4

Alan KIRMAN/Louis PHLIPS

Empirical Studies of Product Markets

ECO No. 93/5

Grayham E. MIZON

Empirical Analysis of Time Series:

Illustrations with Simulated Data

ECO No. 93/6

Tilman EHRBECK

Optimally Combining Individual

Forecasts From Panel Data

ECO NO. 93/7

Víctor GÓMEZ/Agustín MARAVALL

Initializing the Kalman Filter with

Incompletely Specified Initial Conditions

ECO No. 93/8

Frederic PALOMINO

Informed Speculation: Small Markets

Against Large Markets

ECO NO. 93/9

Stephen MARTIN

Beyond Prices Versus Quantities
ECO No. 93/10

José María LABEAGA/Angel LÓPEZ

A Flexible Demand System and VAT

Simulations from Spanish Microdata

ECO No. 93/11

Maozu LU/Grayham E. MIZON

The Encompassing Principle and

Specification Tests

\section{ECO No. 93/12}

Louis PHLIPS/Peter MØLLGAARD

Oil Stocks as a Squeeze Preventing

Mechanism: Is Self-Regulation Possible?

ECO No. 93/13

Pieter HASEKAMP

Disinflation Policy and Credibility: The

Role of Conventions

ECO No. 93/14

Louis PHLIPS

Price Leadership and Conscious

Parallelism: A Survey

ECO No. 93/15

Agustín MARAVALL

Short-Term Analysis of Macroeconomic Time Series 


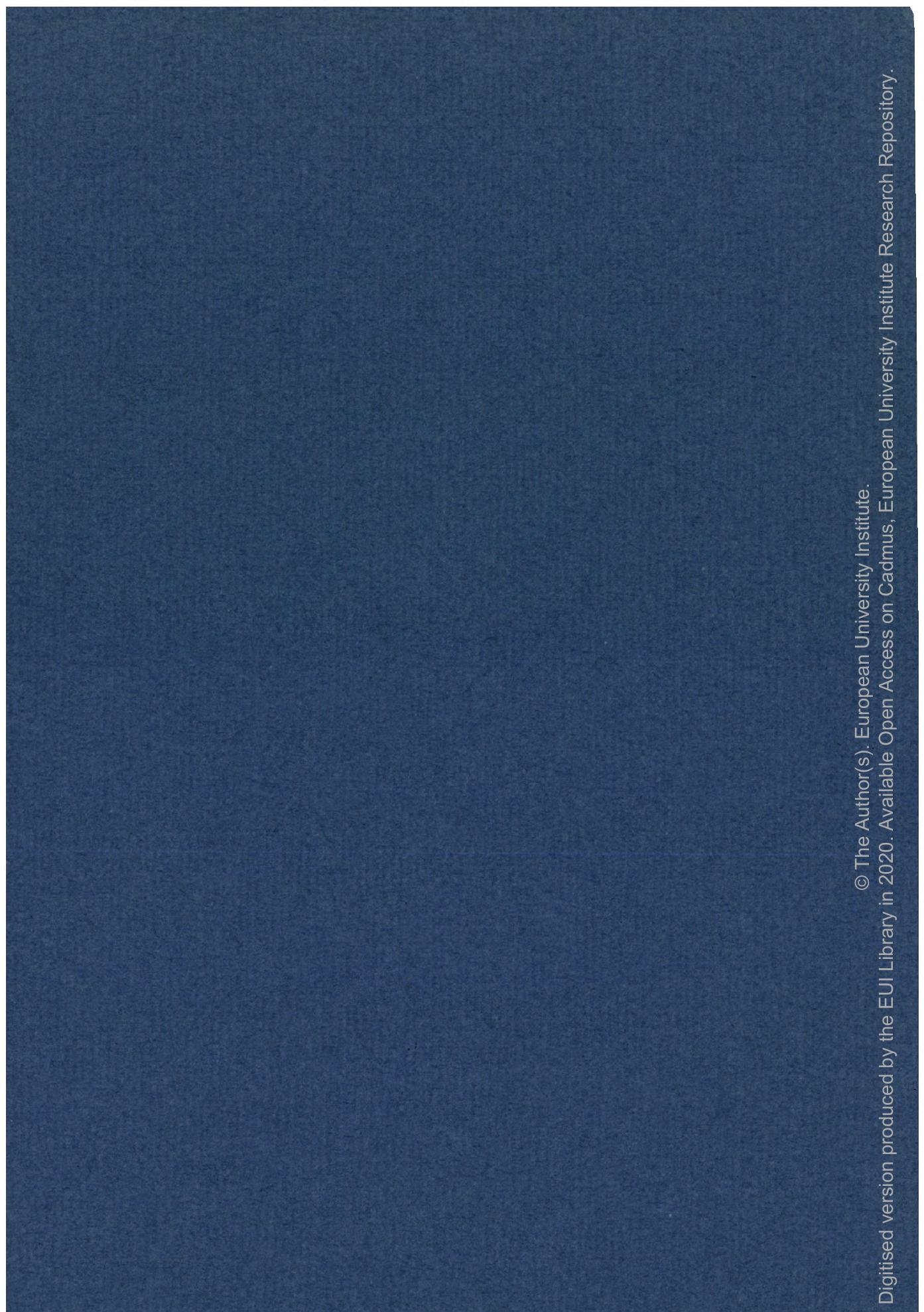


